\title{
Diabetic cardiomyopathy: from the pathophysiology of the cardiac myocytes to current diagnosis and management strategies
}

This article was published in the following Dove Press journal:

Vascular Health and Risk Management

8 October 2010

Number of times this article has been viewed

\section{Christina Voulgari \\ Dimitrios Papadogiannis \\ Nicholas Tentolouris \\ First Department of Propaedeutic and Internal Medicine, Athens University \\ Medical School, Laiko General \\ Hospital, Athens, Greece}

Correspondence: Christina Voulgari 24 Olenou St, Athens II 3 62, Greece

Tel +30 2I 07456448

Fax +30 210 7462640

Email c_v_24@yahoo.gr

\begin{abstract}
Diabetic cardiomyopathy (DCM), although a distinct clinical entity, is also a part of the diabetic atherosclerosis process. It may be independent of the coexistence of ischemic heart disease, hypertension, or other macrovascular complications. Its pathological substrate is characterized by the presence of myocardial damage, reactive hypertrophy, and intermediary fibrosis, structural and functional changes of the small coronary vessels, disturbance of the management of the metabolic cardiovascular load, and cardiac autonomic neuropathy. These alterations make the diabetic heart susceptible to ischemia and less able to recover from an ischemic attack. Arterial hypertension frequently coexists with and exacerbates cardiac functioning, leading to the premature appearance of heart failure. Classical and newer echocardiographic methods are available for early diagnosis. Currently, there is no specific treatment for DCM; targeting its pathophysiological substrate by effective risk management protects the myocardium from further damage and has a recognized primary role in its prevention. Its pathophysiological substrate is also the objective for the new therapies and alternative remedies.
\end{abstract}

Keywords: cardiovascular disease, atherosclerosis, cardiac autonomic neuropathy, echocardiography, treatment strategies

\section{Introduction}

Cardiovascular disease is a common complication of diabetes responsible for $80 \%$ of the mortality in the diabetic population. ${ }^{1}$ Coronary artery disease is the leading cause for the increased cardiovascular morbidity and mortality in diabetes, and atherosclerosis of the coronary vessels is its initial pathogenetic mechanism. Coronary artery disease and hypertension can account for most of the myocardial abnormalities (left ventricular [LV] hypertrophy and impaired contractility) that occur in diabetes. However, postmortem, experimental, and observational studies also provide evidence for a specific cardiomyopathy in diabetes, which may contribute to myocardial dysfunction in the absence of coronary artery atheroma. ${ }^{2}$ This is also sustained by the fact that patients with diabetes, independently of the severity of coronary artery disease, have increased risk of heart failure in comparison with subjects without diabetes. ${ }^{3,4}$

In 1972 for the first time in medical history, the description of 4 patients with diabetes and heart failure but without arterial hypertension or coronary artery disease appeared. The anatomical dissection of their hearts revealed LV hypertrophy and fibrosis without evidence of coronary artery atheroma or another substrate pathology responsible for these findings. This clinical entity (disease) was considered as independent and was baptized "diabetic cardiomyopathy" (DCM). ${ }^{5}$ 
The aim of this review is to provide up-to-date information on the pathophysiology, diagnosis, and management of DCM. We performed a comprehensive search in the PubMed and Embase databases up to February 2010 using the following keywords alone and in combination to retrieve available literature data: "diabetes mellitus", "cardiomyopathy", "cardiac myocytes," "pathophysiology", "hyperglycemia”, "insulin resistance", "risk factors", "myocardial performance", "diastolic dysfunction", "heart failure", "diagnosis", and "treatment". All types of articles (randomized controlled trials, original studies, review articles, and case reports) in humans and animals published in English language were included. Publications were studied in detail.

\section{Epidemiological data on DCM}

Epidemiological evidence has demonstrated worldwide that macrovascular complications (coronary artery disease, peripheral vascular disease, and stroke) are more common (2-4 times) among diabetes patients in comparison with the nondiabetes subjects. This is valid for both type 1 and type 2 diabetes even when all other cardiovascular risk factors, such as hypertension, obesity, smoking, dyslipidemia, age, and sex, are taken into consideration. ${ }^{6}$

The Framingham Study showed that the frequency of coronary artery disease is twice more common in diabetes patients of both sexes, since women with diabetes appear to lose their normal premenopausal protection against cardiovascular disease. Moreover, death from coronary artery disease is 3 times more common in diabetes patients compared with nondiabetes subjects matched by age and sex. In other words, a patient with diabetes is not only at high risk of developing coronary artery disease, but furthermore, he is more susceptible to a worse prognosis. ${ }^{4}$ Atheromatous lesions have an earlier onset, faster development, and greater density in diabetes. ${ }^{7}$ The risk of coronary artery disease increases rapidly after the age of 40 in patients with type 1 diabetes, and by the age of $55,35 \%$ of the patients of both sexes have died because of a coronary artery event, compared with $8 \%$ of men and $4 \%$ of women in the general population. ${ }^{8}$

It should be noted that in the last 30 years, the substantial decrease in cardiovascular mortality in men without diabetes (up to $36.4 \%$ ) was not followed by a decrease in the cardiovascular mortality among the male diabetic population (up to $13.1 \%$ decline). Even more disappointing were the results among women. Although cardiovascular mortality in women without diabetes was reduced by $17 \%$, it was increased by $23 \%$ in the female diabetic population. ${ }^{9}$ This supports even further the loss of the premenopausal protection against coronary artery disease in diabetes seen in healthy women. The STENO-2 Study demonstrated that in patients with type 2 diabetes, even when all associated cardiovascular risk factors are treated and the incidence of cardiovascular events is decreased by $50 \%$, the cardiovascular mortality still remains high. ${ }^{10}$

In one prospective study that included a population of 1,059 patients with diabetes and 1,373 subjects without diabetes, who were followed up for at least 7 years, it was concluded that the frequency of mortality in patients with diabetes but without myocardial infarction was similar to that in subjects without diabetes but with myocardial infarction. ${ }^{11}$ Moreover, in patients with diabetes and acute myocardial infarction, mortality during the first month is above $42 \%$, whereas in subjects without diabetes, it is less than $20 \%{ }^{12,13}$ Some studies have demonstrated that good glycemic control is associated with higher survival rates after acute myocardial infarction. ${ }^{14}$ In diabetes subjects with angiographically proven coronary artery disease, the survival rates are decreased by $30 \%$ compared with their nondiabetes counterparts. ${ }^{15}$ Diabetic nephropathy, which often coexists, especially proteinuria, increases further the risk of cardiovascular death. ${ }^{16}$ Moreover, a significant association between idiopathic cardiomyopathy and diabetes was recently described. ${ }^{17}$

An important consequence of DCM is heart failure, which is more common in people with diabetes and complicates acute myocardial infarction more often than in the nondiabetic population. The increased percentage of patients with diabetes and heart failure in numerous multicenter epidemiological studies is in contrast to the total diabetic burden in the general population $(6 \%-8 \%)$. In the Studies of Left Ventricular Dysfunction (SOLVD), the percentage of patients with diabetes and heart failure was up to $26 \%,{ }^{18}$ whereas in the Assessment Trial of Lisinopril and Survival (ATLAS) study, it was $19 \%{ }^{19}$ and in the Vasodilator-Heart Failure Trial II (V-HeFT II), it was up to $20 \%{ }^{20}$

These findings are in agreement for the presence of an additional detrimental factor in the diabetic myocardium, which predisposes it to extensive damage followed by heart failure. Even more, they are supportive for the early treatment of diabetes patients with aspirin and other measures that are used for secondary prevention in the general population, even in the absence of clinically apparent macrovascular complications.

In summary, cardiovascular disease is $2-3$ times more common, and survival is worse in subjects with diabetes in comparison with age-matched and sex-matched counterparts. 
The prevalence of heart failure with preservation of systolic function among patients with diabetes is $19 \%-26 \%$.

\section{Definition of DCM}

DCM is defined as the cardiovascular damage present in diabetes patients, which is characterized by myocardial dilatation and hypertrophy, as well as a decrease in the systolic and diastolic function of the left ventricle, and its presence is independent of the coexistence of ischemic heart disease or hypertension. DCM may be subclinical for a long time, before the appearance of clinical symptoms or signs. According to the molecular theory of DCM, hyperglycemia is the main pathogenetic factor, which causes abnormalities at the cardiac myocyte level, eventually leading to structural and functional abnormalities. ${ }^{21}$

\section{The pathophysiological substrate of DCM \\ The anatomical damage of the myocardial substrate}

Atheromatous plaques in patients with diabetes are not qualitatively different from those affecting the nondiabetic population. However, atheroma in patients with diabetes is more extensive, is more diffuse, and involves distal vessels in both the coronary and peripheral circulation. ${ }^{22}$ Pathologic anatomical alterations of the small coronary vessels and the myocardial endothelium include increased cell adhesiveness, impaired relaxation, impaired fibrinolysis, and increased permability. ${ }^{22}$ The early stages of DCM are dominated by the pathological alterations in the myocardial interstitium, ie, formation of nonenzymatic advanced glycation end products (AGEs), impaired compliance, and ischemia from the disease in the vasa vasorum. The morphology of the myocardial cells and small coronary vessels is anatomically preserved. These alterations lead to impaired myocardial contractility. ${ }^{23}$ As the disease progresses, LV hypertrophy appears as a result of the hypertrophy of the myocardial cells, the interstitial and perivascular fibrosis, the greater thickening of the capillary basement membrane, and the formation of microaneurysms in small capillary vessels. This ultimate observation may be the actual pathophysiological connection between diabetes microvascular and macrovascular disease. ${ }^{24}$

\section{Structural alterations leading to ventricular dysfunction}

Medial layers of arterioles throughout the cardiac circulation in diabetes show "hyaline" change, an amorphous, ground glass appearance, resulting from breakdown of structural proteins (largely thought to be collagen) and the uptake of glycated plasma proteins into the vessel wall. Similar changes are seen in older nondiabetes subjects as part of the aging process and in hypertension. The reduced blood supply resulting from microvascular disease and affecting the vasa vasorum in diabetes further damages the small and medium arterioles of the diabetic heart. A clear relationship between the loss of cardiac function and the histological damage in the diabetic blood vessels is very difficult to demonstrate. However, it is plausible that the structural changes and loss of elasticity contribute to hypertension and possibly to the greatly increased risk of macrovascular events in diabetes. The European Heart Association's Guidelines (2009) have defined LV hypertrophy as an increase in LV mass index above $125 \mathrm{~g} / \mathrm{m}^{2}$ for men and above $110 \mathrm{~g} / \mathrm{m}^{2}$ for women. The Framingham Study demonstrated that the determination of LV hypertrophy electrocardiographically was not associated significantly with increased cardiovascular morbidity and mortality. ${ }^{25}$ However, in the Framingham Study, when LV hypertrophy was assessed echocardiographically in a population of 3,222 patients, it was demonstrated that the relative risk for cardiovascular mortality for each $50 \mathrm{~g} / \mathrm{m}^{2}$ increase of the LV mass above the normal limits was equal to 1.49 for men and 1.57 for women. ${ }^{26}$

LV hypertrophy is significantly associated with an increase in markers of systemic inflammation, such as fibrinogen, C-reactive protein, and microalbuminuria. In one study including 1,299 patients with type 2 diabetes, microalbuminuria not only was a marker of endothelial dysfunction and increased risk of atherosclerosis but also was positively associated with LV mass. ${ }^{27}$

\section{Functional alterations of DCM}

Uncomplicated reduction of systolic myocardial functioning is defined as the loss of the heart's ability to pump arterial blood in the peripheral circulation. However, the elementary difference between the uncomplicated reduction of systolic myocardial function and systolic heart failure is that in the latter, the clinical symptoms and signs of heart attack appear as a result of the former. Thus, the main guidance point of systolic myocardial dysfunction is the reduction of the LV ejection fraction.

However, recent studies revealed that the classical 2-dimensional echocardiography (2DE) may not be able to detect and diagnose the early uncomplicated reduction of the LV systolic myocardial functioning. This is due to the fact that classical $2 \mathrm{DE}$ can determine only $\mathrm{LV}$ 
circumferential function and cannot estimate LV longitudinal functioning. ${ }^{28}$

In DCM, progression and appearance of reduction of systolic function is slow, often when patients have already developed a significant reduction of diastolic myocardial functioning. The prognosis of patients with LV systolic myocardial dysfunction is poor, and the percentage of annual mortality is equal to $15 \%-20 \%$.

Diastole is defined as the period when the myocardial muscle generates effort and energy, while in mechanical (isovolumic deceleration and relaxation phase) and electrophysiological inactivity (automatic depolarization). ${ }^{29}$ Reduction of diastolic myocardial functioning is determined by a delayed and extended diastolic phase. Diastolic dysfunction is also characterized electrophysiologically by the prolongation of the active dilatation and the augmented passive stiffness of the left ventricle, which portray the passive diastolic LV compliance in heart failure. ${ }^{30}$ Impaired diastolic functioning of the left ventricle appears in $27 \%-69 \%$ of the cardiovascular asymptomatic population with diabetes ${ }^{31}$ and is responsible for the $30 \%$ of the patients ending up with diabetes and clinical symptomatic heart failure. ${ }^{32}$ Impaired diastolic compliance and maintenance of the systolic function is usually the initial heart lesion in the progression of DCM. ${ }^{33}$ Failure of diastolic relaxation of the left ventricle leads to impaired filling and reduced cardiac reserve on exercise. In spite of the absence of systolic dysfunction, numerous clinical studies have demonstrated a decreased ejection fraction, which determines reduced cardiac residual reserve in asymptomatic patients with diabetes. ${ }^{34}$ Subclinical DCM characterized by reduced cardiac residual reserve can develop into a significant clinical entity, especially when myocardial ischemia coexists or suddenly appears.

Diastolic myocardial function can be evaluated by cardiac catheterization for the evaluation of the isovolumic relaxation rhythm and the LV isovolumic contraction time. ${ }^{35}$ This method, although highly accurate, for the evaluation of LV diastolic function is invasive and has increased possibilities of accidental injury. The alternative noninvasive techniques include classical 2DE and M-mode echocardiography with Doppler. LV diastolic functioning can also be evaluated by controlling the transmitral and pneumocardial blood flow. ${ }^{36}$

The medical term "diastolic dysfunction" refers exclusively to the echocardiographic finding of an abnormal LV deceleration and relaxation time, without the coexistence of any clinical evidence suggestive of heart failure. However, diastolic heart failure is defined as the clinical syndrome of heart failure with preservation of a normal LV ejection fraction. Echocardiographic findings of isolated myocardial dysfunction, such as subclinical reduction of myocardial diastolic compliance and loading, are reliable prognostic markers of future chronic heart failure. ${ }^{37}$ Moreover, patients with diastolic heart failure have increased cardiovascular mortality (equal to 5\%-8\%) compared with healthy subjects matched by age and sex (equal to $1 \%$ ). ${ }^{38-40}$

The impact of diastolic dysfunction is associated with good glycemic control, as assessed by hemoglobin $\mathrm{A}_{1 \mathrm{c}}\left(\mathrm{HbA}_{1 \mathrm{c}}\right)$ levels. ${ }^{41}$ Possibly, the main cause for this relationship are the increased circulatory $\mathrm{AGEs}^{42}$ and the increased production of free oxygen radicals, ${ }^{43}$ resulting in an increased accumulation of collagen in the myocardium and in myocardial fibrosis. ${ }^{44,45}$

Coexistent hypertension accelerates the functional underlying process, leading to LV hypertrophy, systolic ventricular dysfunction, and greatly increased risk of congestive heart failure. Although, it is difficult to disentangle the effects of hypertension from the other facets of the pathophysiology of ventricular dysfunction in diabetes, LV hypertrophy has also been observed in nonhypertensive individuals with diabetes, and particularly in women. ${ }^{46}$

In conclusion, DCM is characterized by LV hypertrophy and myocardial dilatation, which lead to LV diastolic and systolic dysfunction. These are related to diabetic fibrosis, inflammation, ischemia, and presence of microvascular complications. DCM is independent of the coexistence of ischemic heart disease or hypertension.

\section{The molecular substrate of DCM}

Hyperglycemia causes significant functional alterations to the cellular $\mathrm{Na}^{+}-\mathrm{Ca}^{2+}$ ionic channel, resulting in a decreased extrapolation and an increased intracellular concentration of ionic calcium. Moreover, in diabetes, a dysfunction of the cellular $\mathrm{Na}^{+}-\mathrm{K}^{+}$ionic channel appears, which primarily causes an increase in the intracellular sodium concentration and secondarily an additional increase to the already augmented intracellular calcium concentration in the diabetic cardiac myocytes. $^{47}$

Dyslipidemia and increased production of free oxygen radicals ${ }^{48,49}$ may cause metabolic alterations to the genetic transcription factors and coding. ${ }^{50,51}$ The result of these alterations is a modification in the translation of nucleoprotein genes, such as RAS and insulin-like growth factor 1 (IGF-1), responsible for the myocardial substrate and myocardial fiber structure and also for the maintenance of a normal myocardial compliance. ${ }^{52,53}$ Accordingly, increased expression of the early cardiopathology-related gene RAS predisposes to 
insulin resistance, whereas the IGF-1 increases myocardial contractility through an increase of the intracellular calcium accumulation and by intensifying the sensitivity of the cardiac myofibers to the circulatory calcium concentration. ${ }^{54}$ IGF-1 is present in the cardiac myocytes, and its expression is augmented by decreased insulin concentration, increased mechanical stress, and increased peripheral vascular resistance. IGF-1 acts synergically with angiotensin II in promoting cellular development. As a result, this leads to myocardial hypertrophy of the diabetic heart ventricle mass even when blood pressure levels are within the normal range. ${ }^{55}$

Thus, hyperglycemia, dyslipidemia, and increased production of free oxidant radicals are main metabolic pathogenetic risk factors leading to DCM.

\section{The interplay of cardiac autonomic neuropathy in DCM}

Cardiac autonomic neuropathy (CAN) is a common complication of diabetes, causing abnormalities in heart rate control and in central and peripheral vascular dynamics. CAN affects almost $17 \%$ of the patients with type 1 and $22 \%$ of those with type 2 diabetes. An additional $9 \%$ of patients with type 1 and $12 \%$ of those with type 2 diabetes have milder forms of autonomic dysfunction. ${ }^{56}$

Several studies have confirmed that cardiac neuropathy has the propensity to cause a reduction in the cardiac ejection fraction, impair systolic dysfunction and decrease diastolic filling, thus having an important contribution to the deterioration of diastolic myocardial function and DCM. Abnormalities of LV diastolic filling are overstated in patients with diabetes and CAN in comparison with patients with diabetes but without this complication. ${ }^{57}$ When LV function was assessed in a diabetic population by resting and exercise radionuclide ventriculography, an abnormal LV performance was revealed in $37 \%$ of the patients included in the study. CAN was present in $59 \%$ of the subjects with DCM, a significantly increased incidence compared with that of $8 \%$ in the patients without this complication. Moreover, there were significant reductions in the ventricular ejection fraction at rest and with maximal exercise in patients with CAN compared with those without this complication. ${ }^{58}$

In a population of subjects with type 1 (insulin-dependent) diabetes, a decrease of the diastolic myocardial function to $21 \%$ was also demonstrated. None of the patients included in the study had clinical evidence of coronary artery disease, and diastolic myocardial dysfunction (impaired diastolic
LV filling) was significantly associated with the presence of CAN. ${ }^{59}$

CAN is portrayed by a significant reduction in heart rate variability and an alteration in the parasympathetic-sympathetic balance, in which a reduction in parasympathetic tone secondary to autonomic neuropathy leads to a relative overactivity of the sympathetic system. Patients with diabetes and mild CAN have been shown to have distal LV sympathetic denervation, whereas patients with severe CAN have a pattern of distal sympathetic denervation associated with proximal ventricular islands of hyperinnervation. These areas of denervation and hyperinnervation may cause unstable regions of electrical, vascular, or autonomic heterogeneity conducive to DCM. ${ }^{60}$

Numerous studies have demonstrated a significant correlation between dysfunction of the parasympathetic nervous system activity and impaired myocardial function. One study evaluated the role of parasympathetic nervous system activity in cardiovascular performance on a group of clinically asymptomatic type 2 diabetes patients, ie, without any symptom, sign, or objective measurement of ischemia or cardiomyopathy. Although patients with CAN corresponded positively to the increase in oxygen uptake by an equivalent percent increase in cardiac output, this response was significantly reduced compared with that of patients without CAN. Thus, it was shown that impaired sympathetic and parasympathetic responses, which normally augment cardiac output and redirect peripheral blood flow to skeletal muscles during exertion, may limit exercise tolerance. ${ }^{61}$

The relationship between parasympathetic nervous dysfunction and DCM was confirmed by an important decrease of heart rate variability during deep breathing maneuver in subjects with type 1 diabetes and by the presence of pathological echocardiographic findings of the LV filling rhythm. ${ }^{62}$

Dysfunction of the sympathetic nervous system activity has been associated with a decrease in both systolic and diastolic myocardial function in subjects with type 2 diabetes. ${ }^{63}$ A significant association between a decrease of the transmitral ratio of early to late peak mitral filling wave velocities and the augmentation of sympathetic myocardial neurosis has also been demonstrated. ${ }^{64}$ This relationship has confirmed that in DCM, the abnormal cardiac sympathetic neurosis contributes to the abnormal LV filling. The transmitral ratio of early to late peak mitral filling has also been associated with orthostatic hypotension as a clinical manifestation of CAN.${ }^{46}$ Moreover, the same index of abnormal cardiac filling was associated with an abnormal expiration/inspiration ratio, ie, an index of parasympathetic dysfunction in patients with 
type 1 diabetes and CAN. ${ }^{65}$ Finally, CAN is associated with a decrease of the elastic vascular properties and an increase of peripheral vascular resistance due to the augmentation of the sympathetic nervous tone. ${ }^{66}$

Resting tachycardia reduces the heart's ability to pump blood in the peripheral circulation and interferes with the ventricular chambers' capacity to fill with blood properly. Ventricular tachycardia not only reduces the time of ventricular filling but also interferes with the timely atrial contraction. When the heart's labor capacity is greatly reduced for a prolonged period, cardiac arrest and death are likely to happen. ${ }^{67}$ Through predisposition to arrhythmias, CAN may lead to LV dysfunction followed by sudden death. ${ }^{68}$ Recent studies revealed that classical ${ }^{69,70}$ and newer markers of arrhythmogenicity ${ }^{71}$ are increased in subjects with diabetes and CAN in comparison with subjects with diabetes but without this complication. Moreover, one recent study revealed that increased markers of spatial ventricular heterogeneity in type 2 diabetes subjects and CAN are associated with the structural and functional properties of the myocardium. ${ }^{71}$

In conclusion, CAN is strongly and independently associated with the structural and functional pathogenetic substrate of DCM in both type 1 and type 2 diabetes patients. This is partially explained by the significant reduction in heart rate variability present in autonomic neuropathy, and an alteration in the parasympathetic-sympathetic balance of the heart, leading to parasympathetic reduction and sympathetic overactivity.

\section{Risk factors for DCM Hyperglycemia}

Hyperglycemia could contribute to macrovascular disease through various mechanisms. Hyperglycemia causes significant functional alterations to the cellular $\mathrm{Na}^{+}-\mathrm{Ca}^{2+}$ ionic channel, resulting in a decreased extrapolation and an increased intracellular concentration of ionic calcium. Moreover, in diabetes, a dysfunction of the cellular $\mathrm{Na}^{+}-\mathrm{K}^{+}$ionic channel appears, which primarily causes an increase in the intracellular sodium concentration and secondarily an additional increase to the already augmented intracellular calcium concentration in the diabetic cardiac myocytes. ${ }^{47}$ However, the most convincing pathogenetic mechanism of hyperglycemia is via the formation of AGEs. AGEs cross-link vessel wall proteins, therefore causing thickening and leakage of the vasculature and forming irreversible and abnormal deposits of plasma-derived proteins in the myocardial subintimal arterial layers. ${ }^{72}$ Furthermore, AGEs generate toxic reactive oxygen species (ROSs) that impair cellular interactions and damage myocardial vascular function, causing endothelial vasomotor dysfunction. ${ }^{73}$

Some of the effects of AGEs are mediated through specific receptors (RAGE) expressed by vascular endothelial, smooth muscle cells and cardiac myocytes. In the cardiac endothelium, AGE-RAGE interaction leads to upregulation of procoagulant and adhesive proteins, including tissue factor, plasminogen activator inhibitor 1 (PAI-1), and vascular cell adhesion molecule 1 (VCAM-1). Expression of VCAM-1 results in an increase in monocyte adhesion, while monocytes expressing RAGE are recruited by chemotaxis to sites of AGE accumulation. There they infiltrate the myocardial subendothelium to form foam cells, an early step in atherogenesis. Other extracellular RAGE ligands are the RAGE-binding proteins that interact with RAGE on cardiac myocytes to induce expression of tumor necrosis factor $\alpha$ (TNF- $\alpha$ ), VCAM-1, nuclear factor $\kappa \mathrm{B}(\mathrm{NF}-\kappa \mathrm{B})$, and interleukin 1 , thus modulating the inflammatory component of cardiovascular disease through the cytokine cascade. ${ }^{74}$

A strong relationship between glycemic control and DCM has been demonstrated in major multicenter prospective studies. The Diabetes Conventional and Complications Trial (DCCT) showed that patients with diabetes who are conventionally treated have a nearly double incidence of DCM when compared with patients with diabetes who are intensively treated. Among the risks for DCM, beyond glycemic control, were increased levels of serum cholesterol and triglycerides. ${ }^{75}$ For each $1 \%$ reduction in $\mathrm{HbA}_{1 \mathrm{c}}$, the United Kingdom Prospective Diabetes Study (UKPDS) demonstrated a $14 \%$ reduction in myocardial infarction. ${ }^{76}$ Moreover, impaired glucose tolerance has been identified as a risk factor for DCM, suggesting that even mild hyperglycemia may contribute to DCM. ${ }^{77}$

\section{Insulin resistance and the metabolic syndrome}

Insulin resistance and hyperinsulinemia have been identified as risk factors for DCM. ${ }^{78,79}$ In hyperinsulinemia and insulin resistance, an imbalance in the direct effects of insulin action occurs, accompanied by the confounding effects of other cardiovascular risk factors associated with the insulin resistance syndrome, ie, central obesity, hyperglycemia, hypertriglyceridemia, low high-density lipoprotein (HDL), and hypertension. ${ }^{80}$ The clustering of these cardiovascular and atherothrombotic risk factors that accompany insulin resistance provides a plausible basis for DCM and is often associated with adverse cardiovascular effects. ${ }^{81,82}$ Hyperinsulinemia and insulin resistance are also associated 
with a cluster of thrombotic risk factors, such as elevated levels of PAI-1, ${ }^{83,84}$ factor VII, factor XII, and fibrinogen. ${ }^{85-87}$ Increased levels of factor VII and XII may also occur through activation by triglyceride-rich particles, whereas hyperfibrinogenemia may be attributed to smoking, increased body mass, and inflammatory responses.

Insulin resistance is often associated with a combination of established and emerging risk factors, including hypertension and C-reactive protein. ${ }^{88,89} \mathrm{C}$-reactive protein is an acute-phase inflammation marker that has been associated with an increased risk for DCM..$^{90,91}$ Recent studies have confirmed the association between increased levels of C-reactive protein and worse LV myocardial performance, as well as risk factors for atherosclerosis and cardiovascular disease in subjects with metabolic syndrome (MetS). ${ }^{92}$ MetS status per se was found to be the strongest predictor of cardiomyopathy, thus implying that the clustering of the metabolic disturbances has additional prognostic information than its individual components in terms of myocardial performance and may explain in part the excess cardiovascular risk present in the MetS. ${ }^{92}$

In conclusion, the effects of insulin on the diabetic heart are related to both systemic metabolic abnormalities and the direct effects of insulin action on the vasculature. Although, the elevation and the imbalance of the cardiovascular and atherothrombotic metabolites and cytokines related to hyperinsulinemia and insulin resistance have a crucial contribution in the pathogenesis of DCM, it should be noted that the direct action of insulin on the vasculature has also been proposed to mediate a combination of proatherogenic and antiatherogenic effects related to endothelial function and smooth muscle cell growth. ${ }^{93}$ The importance of insulin resistance and the MetS is further confirmed by the fact that insulin-resistant individuals who are either hyperinsulinemic and normoglycemic ${ }^{79}$ or hyperinsulinemic with impaired glucose tolerance ${ }^{94}$ show a similarly high-risk profile to those with overt diabetes, whereas others who are destined to develop diabetes, but lack insulin resistance, are not at increased risk. ${ }^{81,95}$

\section{Dyslipidemia}

Increased atherogenesis and insulin resistance in diabetes and MetS have been attributed in large part to a proatherothrombotic dyslipidemia, related to hypertriglyceridemia, elevated very low-density lipoprotein, and decreased HDL cholesterol levels. ${ }^{96,97}$ Insulin resistance results in increased levels of triglyceride-enriched, small, dense low-density lipoprotein (LDL) particles, which have been associated with an increased risk of ischemic heart disease. ${ }^{98}$ Moreover, the combined elevation of fasting insulin, apoprotein B, and small, dense LDL particles has been identified as a nontraditional risk factor cluster for coronary artery disease. ${ }^{99}$ Dyslipidemia has been recently associated with worse myocardial performance in type 2 diabetes subjects ${ }^{100}$ and in the MetS. ${ }^{92}$ Additional risk factors for DCM associated with dyslipidemia include increased lipoprotein(a) ${ }^{101}$ and nonesterified fatty acids. ${ }^{102}$

\section{Hypertension}

Hypertension commonly coexists with type 1 and type 2 diabetes. Hypertension per se is a major risk factor for vascular complications, ie, myocardial infarction and stroke. ${ }^{103,104}$ According to major multicenter studies, the majority (almost $50 \%$ ) of patients with diabetes and no clinical evidence of atheromatous disease are hypertensive or are taking antihypertensive drugs. In diabetes subjects with DCM, the prevalence of hypertension is even higher. ${ }^{105}$ Insulin resistance has been proposed to be the fundamental cause of hypertension and DCM in type 2 diabetes. ${ }^{106}$ Acquired factors such as obesity and physical inactivity may also contribute. Hypertension is an important feature of the cluster of the cardiovascular risk factors included in the MetS. The relationship between these metabolic components is complex and in part largely unexplained. Insulin resistance could raise blood pressure by the loss of insulin's normal vasodilator activity, ${ }^{107}$ or through effects of the accompanying hyperinsulinemia. These include $\mathrm{Na}^{+}$and water retention, increased intracellular $\mathrm{Na}^{+}$concentrations ${ }^{108}$ that enhance the contractility and stimulate proliferation of vascular smooth muscle, ${ }^{109}$ increase peripheral resistance, and cause sympathetic overactivity. ${ }^{110}$ In other words, hypertension and DCM are synergic and share similar pathogenetic pathways. The characteristic dyslipidemia of insulin resistance that contributes to DCM may also contribute to hypertension, as small, dense LDL particles are especially susceptible to oxidation, and oxidized LDL can suppress endothelial nitric oxide production and so promote vasoconstriction; hypertriglyceridemia also impairs endothelium-dependent vasorelaxation. ${ }^{11}$ Studies have shown that fibrates used to treat hypercholesterolemia also reduce the prevalence of hypertension up to $25 \%$. $^{112}$

\section{Obesity}

Obesity predisposes to type 2 diabetes, hypertension, dyslipidemia, and ultimately atheroma, which is one of the major causes of premature death in obese people. ${ }^{113}$ Obesity is recognized as an independent cardiovascular risk factor. ${ }^{114}$ Central obesity is characterized by excess fat deposited 
both subcutaneously around the abdomen and within the visceral cavity and is commonly found in patients with type 2 diabetes and MetS. Central obesity is associated with insulin resistance and proinflammatory responses that cause glucose intolerance and a highly atherogenic-risk profile. Adipose tissue produces nonesterified fatty acids and cytokines such as TNF- $\alpha$ that may contribute to both insulin resistance and atherogenesis. Reduced levels of adiponectin, an insulinsensitizing protein whose secretion by adipose tissue is paradoxically decreased in obesity, may also contribute to insulin resistance and DCM. ${ }^{115}$ Indeed, in a recent study, central obesity, as part of the MetS, was significantly and independently associated with LV myocardial dysfunction. ${ }^{116}$

\section{The effect of diabetic nephropathy}

Nephropathy is a common complication affecting almost one-third of patients with diabetes. ${ }^{117}$ Both microalbuminuria (albumin excretion rate of 30-299 $\mathrm{mg} / 24 \mathrm{~h}$ ) and proteinuria (albumin excretion, $>300 \mathrm{mg} / 24 \mathrm{~h}$ ) are markers of increased cardiovascular risk. ${ }^{118,119}$ In type 1 diabetes, the relative risk of DCM is 1.2-fold in patients with microalbuminuria ${ }^{120}$ and 10 -fold in patients with proteinuria ${ }^{121}$ compared with patients with normoalbuminuria. In type 2 diabetes, the risk of DCM is increased 2- to 3-fold in microalbuminuria ${ }^{122}$ and 9-fold in proteinuria. ${ }^{123}$

The onset of microalbuminuria is associated with an excess of cardiovascular risk factors, including hyperglycemia, dyslipidemia, and numerous prothrombotic and atherogenic changes. ${ }^{124,125}$ Moreover, there is growing evidence that the genetic susceptibility influences the development of diabetic nephropathy and also affects the diabetic cardiovascular system. ${ }^{126}$ Suggested mechanisms linking renal and cardiovascular disease include endothelial dysfunction, abnormalities of the renin-angiotensin system, and widespread vascular basement membrane defects.

In conclusion, the pathogenic contribution to the development of DCM includes insulin resistance, increased formation of AGEs, MetS, hyperglycemia, dyslipidemia, obesity, and presence of microangiopathy. Their interplay is complex, since they can act in parallel and synergically and, at the same time, have a cause and effect result. Thus, they should be equally predicted and effectively treated. The contribution of the various factors in the development of DCM is depicted in Figure 1.

\section{The diagnostic paths through DCM}

Echocardiography is a reliable, noninvasive technique for the determination of LV hypertrophy and the reduction of both

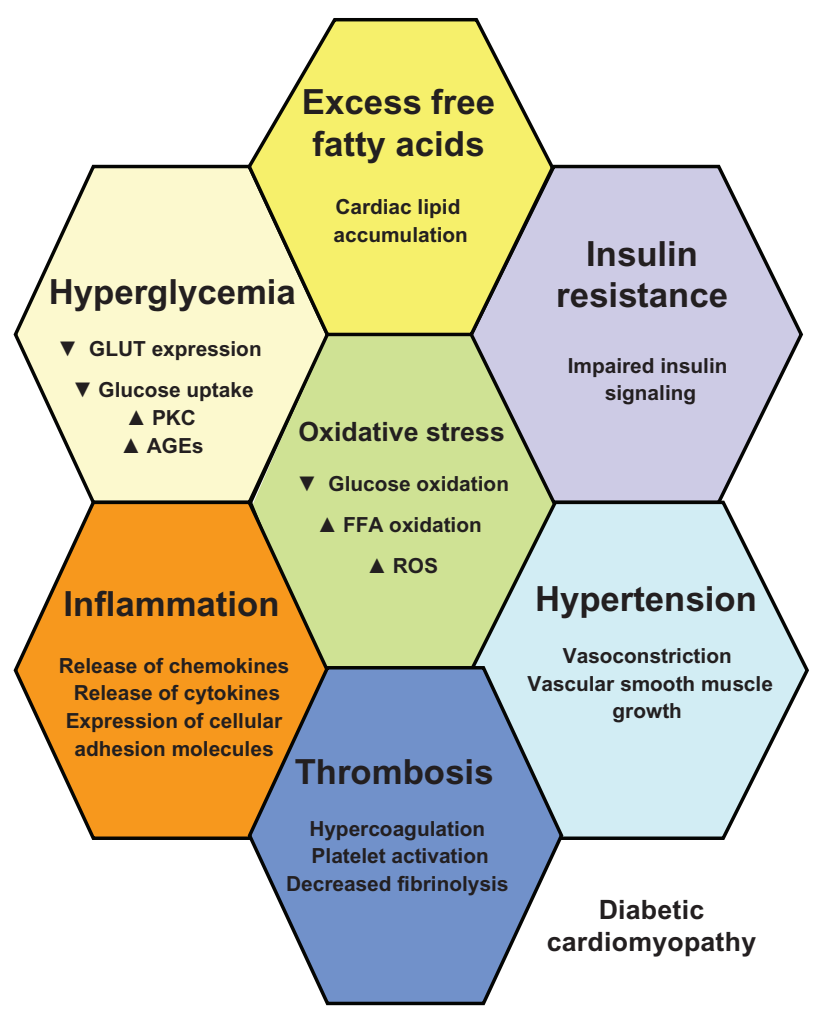

Figure I The pathophysiological substrate of diabetic cardiomyopathy: in diabetes, hyperglycemia, excess free fatty acid (FFA) release, and insulin resistance, engender adverse metabolic events that affect the cardiac myocytes. Hyperglycemia is associated with decreased glucose transportation (GLUT), uptake, and oxidation, as well as increased formation of advanced glycation end products (AGEs) and increased activation of protein kinase C (PKC). Excess FFA release is followed by cardiac lipotoxicity, ie, increased cardiac lipid accumulation and increased generation of reduced reactive oxygen species (ROS) at the level of the electron transport chain. Together with insulin resistance and impaired insulin action and signaling, these metabolic paths augment vasoconstriction, produce and further aggravate arterial hypertension, increase inflammation with liberation of leukocyte-attracting chemokines, increase production of inflammatory cytokines, and augment expression of cellular adhesion molecules. Thrombosis is further promoted, together with platelet activation.

systolic and diastolic myocardial function. Moreover, it has a prognostic value for the early diagnosis of DCM.

\section{The classical echocardiographic markers of DCM: advantages and disadvantages}

Early deteriorations of myocardial function are characterized by a normal ejection fraction and a decrease in ventricle filling during the initial phase of diastole. Prolongation of isovolumic myocardial relaxation and an increase in atrial filling further confirm a decrease in diastolic myocardial function. The Framingham study showed an increase of LV mass in women with diabetes, independent of the effects of other traditional risk factors. ${ }^{46}$ Subsequent studies confirmed these results in both genders, highlighting associations of both diabetes and glucose intolerance with LV structure abnormalities, independent of the influence of relevant covariates, such as arterial blood pressure levels 
and treatment with angiotensin-converting enzyme (ACE) inhibitors. ${ }^{43,127-130}$ The same was true for patients with type 1 diabetes. ${ }^{131}$ Early echocardiographic studies revealed that half of the diabetic population with decreased myocardial diastolic function remain undiagnosed with the classical echocardiographic techniques. This is due to the fact that the echocardiographic subestimation of the degree of diastolic dysfunction with the classical echocardiographic markers in the subjects with normal arterial blood pressure levels is equal to $60 \%$. $^{132,133}$

\section{The newest echocardiographic markers: their performance structure and role as diagnostic tools}

Total ejection isovolumic (TEI) index is a myocardial performance index and a method for the global estimation of the LV performance. ${ }^{134}$ The TEI index is not influenced by the increased left atrial loading pressure often present in the advanced stages of diastolic heart failure, which is a key advantage compared with the classical echocardiographic methods. ${ }^{135,136}$ The isolated estimation of the decrease in diastolic myocardial function has been recently questioned owing to the presence of reduced systolic function in patients with normal ejection fraction. Therefore, evaluation of TEI index may become a valuable tool for the early diagnosis of upcoming myocardial ischemia. ${ }^{137}$

An important limitation of the single use of TEI index for the estimation of myocardial dysfunction is that it does not allow the evaluation of the pathogenetic substrate of myocardial dysfunction because it cannot evaluate the myocardial pressure levels during diastolic filling or the changes in systolic preload. ${ }^{138}$ However, the clinical significance of TEI index as a diagnostic tool for New York Heart Association Grade I-III heart failure was recently successfully demonstrated and was identical when compared with the results of invasive techniques. ${ }^{139}$ Moreover, TEI index was demonstrated as a significant prognostic marker of cardiovascular morbidity and mortality in elderly patients, independent of the coexistence of the classical cardiovascular risk factors. ${ }^{140}$

In a recent study in type 2 diabetes patients without macrovascular complications, TEI index was significantly and independently associated with the presence of DCM. ${ }^{100}$ Moreover, in type 2 diabetes patients with DCM, higher values of the TEI index were associated with increased ventricular arrhythmogenicity, suggesting a significant association between the underlying LV diastolic dysfunction and the LV electrophysiological activity of the diabetic heart. This association was further supported by the findings of another study in a nondiabetic population with MetS, where worse myocardial function, assessed by higher TEI index values, was associated with increased ventricular arrhythmogenicity. ${ }^{92}$ This study concluded that the electrophysiological abnormalities present in the MetS may be due to the direct effects of hyperinsulinemia on myocardial membrane activity or the electrophysiological alterations that accompany the biochemical and functional abnormalities caused by the shift in the myocardial substrate utilization. ${ }^{141}$

MetS was also associated with worse myocardial performance assessed by the TEI index in a population without diabetes, hypertension, or other macrovascular complications. This association was confirmed for the MetS per se, the sum of its components and its particular components. Additionally, it was demonstrated that factors associated with conditions commonly associated with MetS, such as insulin resistance, low-grade inflammation, and microalbuminuria, were also associated with worse LV myocardial performance. ${ }^{116}$

Other modern echocardiographic techniques, such as transmitral pulsed Doppler and its applications (strain and strain rate), which are less susceptible to the alterations of the cardiac loading conditions, have recently demonstrated $63 \%$ sensitivity against the $50 \%$ of the pulsed Doppler in diagnosing DCM. ${ }^{137,142-144}$ Table 1 shows the main echocardiographic findings and the incidence of DCM in major and recent studies.

\section{Treatment strategies of DCM: risk factors, management and lessons from studies Lifestyle}

Regular physical exercise and limitation of fat and total energy intake remain the cornerstone of the management of overweight diabetes patients who currently represent $80 \%$ of type 2 and at least $25 \%$ of type 1 diabetes patients worldwide. Patients with diabetes should be encouraged to undertake moderate aerobic activity, ie, walking for 30-45 min everyday. Patients with angina or breathlessness on exertion should exercise within their limitations, aiming gradually to increase their activity. In obese patients with a body mass index (BMI) $>30 \mathrm{~kg} / \mathrm{m}^{2}$, an initial target should be $10 \%$ weight loss; in those who are not obese, a target BMI of $\leq 25 \mathrm{~kg} / \mathrm{m}^{2}$ may be reasonable.

One prospective, randomized, controlled study evaluated the effects of diet and exercise on the reduction of the overall incidence of DCM in patients with type 2 diabetes for a follow-up period of 6 years. Subjects were randomized either 
Table I Main and recent echocardiographic, population-based studies on diabetic cardiomyopathy

\begin{tabular}{|c|c|c|c|}
\hline Reference & Population sample & Findings & Incidence of DCM \\
\hline [46] & $\begin{array}{l}\text { I,986 men }+2,529 \text { women } \\
\text { (III with DM }+38 \text { I with IGT) }\end{array}$ & $\begin{array}{l}\uparrow \mathrm{LV} \text { wall thickness, } \uparrow \text { relative wall thickness, } \\
\uparrow \mathrm{LV} \text { end-diastolic dimension, } \uparrow \mathrm{LV} \text { mass }\end{array}$ & $\begin{array}{l}13.9 \% \text { in men } \\
16.1 \% \text { in women }\end{array}$ \\
\hline [127] & $\begin{array}{l}5,20 I \text { men }+ \text { women } \\
(2,697 \text { with } D M \text { or IGT, } \\
\text { age } \geq 65 \text { years })\end{array}$ & $\begin{array}{l}\uparrow \text { ventricular septal thickness, } \uparrow \text { posterior wall } \\
\text { thickness, } \uparrow \text { left ventricular mass, } \uparrow \text { early and late } \\
\text { diastolic transmitral peak flow velocities }\end{array}$ & $40 \%$ in both sexes \\
\hline [43] & 1.810 men + women with DM & $\begin{array}{l}\uparrow \mathrm{LV} \text { mass, } \uparrow \mathrm{LV} \text { wall thicknesses } \downarrow \text { LV fractional } \\
\text { shortening, } \downarrow \text { midwall shortening, } \\
\downarrow \text { stress-corrected midwall shortening }\end{array}$ & $\begin{array}{l}14 \% \text { in women } \\
12 \% \text { in men }\end{array}$ \\
\hline [128] & $\begin{array}{l}\text { I,950 men + women with HTN } \\
(386 \text { with DM) }\end{array}$ & $\begin{array}{l}\uparrow \mathrm{LV} \text { mass, } \uparrow \mathrm{LV} \text { relative wall thickness, concentric LV } \\
\text { geometry, } \downarrow \text { LV stress-corrected midwall shortening, } \\
\downarrow \text { myocardial function ( } \downarrow \text { midwall and } \downarrow \text { stress-corrected } \\
\text { midwall fractional shortening) }\end{array}$ & $38 \%$ in both sexes \\
\hline [129] & $\begin{array}{l}3,628 \text { men + women } \\
(457 \text { men + women with IGT) }\end{array}$ & $\begin{array}{l}\uparrow \mathrm{LV} \text { mass, } \uparrow \text { cardiac index, } \uparrow \mathrm{LV} \text { wall thicknesses and } \\
\uparrow \text { relative wall thickness }\end{array}$ & $12.6 \%$ in both sexes \\
\hline$[130]$ & 173 men + women with DM + HTN & $\uparrow \mathrm{LV}$ mass & $30 \%$ in both sexes \\
\hline$[|3|]$ & 39 boys + girls with type I DM & $\uparrow \mathrm{LV}$ mass, $\downarrow$ LV performance & $30 \%$ in both sexes \\
\hline$[100]$ & I 48 men + women (74 with DM) & $\uparrow \mathrm{LV}$ mass index, $\uparrow \mathrm{TEl}$ index & $34 \%$ in both sexes \\
\hline [92] & $\begin{array}{l}306 \text { men }+ \text { women } \\
\text { (I53 with MetS) }\end{array}$ & $\uparrow \mathrm{LV}$ mass index, $\uparrow$ TEI index & $12 \%$ in both sexes \\
\hline [116] & $\begin{array}{l}550 \text { men }+ \text { women } \\
(275 \text { with MetS) }\end{array}$ & $\uparrow$ TEl index & $18 \%$ in both sexes \\
\hline [142] & $\begin{array}{l}\text { I } 86 \text { type } 2 \text { diabetes patients } \\
\text { with normal ejection fraction }\end{array}$ & $\begin{array}{l}\text { Systolic dysfunction: } \downarrow \text { peak strain and } \downarrow \text { strain rate } \\
\uparrow \text { calibrated IB (myocardial reflectivity) }\end{array}$ & $15.8 \%$ in both sexes \\
\hline [143] & $\begin{array}{l}4 I \text { diabetes patients with normal } \\
\text { resting } L V \text { function and a normal } \\
\text { dobutamine echo }\end{array}$ & $\begin{array}{l}\downarrow \text { peak myocardial systolic velocity } \\
\downarrow \text { early diastolic velocity }\end{array}$ & $\begin{array}{l}16 \% \text { subtle dysfunction } \\
\text { in both sexes }\end{array}$ \\
\hline [137] & 35 type 2 diabetes patients & $\begin{array}{l}\downarrow \text { longitudinal peak systolic velocity at rest and at } \\
\text { peak stress, } \downarrow \text { functional reserve, } \uparrow \text { radial systolic velocity }\end{array}$ & $20 \%$ in both sexes \\
\hline [144] & I 34 type 2 diabetes patients & $\begin{array}{l}\downarrow \text { mean peak systolic early }+ \text { diastolic } \\
\text { velocity, } \downarrow \text { mean isovolumic relaxation time, } \\
\uparrow \text { systolic }+ \text { diastolic synchronicity }\end{array}$ & $20 \%$ in both sexes \\
\hline
\end{tabular}

Abbreviations: DCM, diabetic cardiomyopathy; DM, diabetes mellitus; IGT, impaired glucose tolerance; LV, left ventricular; HTN, hypertension; TEl, total ejection isovolumic; MetS, metabolic syndrome; IB, integrated backscatter.

to a control group or to 1 of the 3 active treatment groups, ie, diet only, exercise only, or diet plus exercise. The cumulative incidence of DCM at 6 years was $67.7 \%$ in the control group compared with $43.85 \%$ in the diet group, $41.1 \%$ in the exercise group, and $46 \%$ in the diet plus exercise group. Each of the active intervention groups differed significantly from the control group $(P<0.05)$. In a proportional hazards analysis comparing the 3 intervention groups to the control group, there was a reduction in the cardiovascular risk of $33 \%$ in the diet group $(P<0.03), 47 \%$ in the exercise group $(P<0.0005)$, and $38 \%$ in the diet plus exercise group $(P<0.005)$. In conclusion, lifestyle changes with diet and/or exercise interventions led to a significant decrease in the incidence of DCM over a 6-year period among subjects with type 2 diabetes. ${ }^{145}$

Another randomized, blinded study with a mean duration of 3.2 years evaluated the feasibility and effects of a program of lifestyle changes designed to prevent or delay the onset of type 2 diabetes in 523 middle-aged, overweight
$\left(\mathrm{BMI} \sim 31.3 \mathrm{~kg} / \mathrm{m}^{2}\right)$ subjects with impaired glucose tolerance and the incidence of DCM in patients with type 2 diabetes. ${ }^{146}$ The intervention group consisted of individualized counseling aimed at reducing weight and total fat intake and increasing fiber intake and physical activity (at least $30 \mathrm{~min}$ per day). During the trial, the risk of diabetes was reduced by $58 \%$ in the intervention group and was directly associated with changes in lifestyle. The changes in lifestyle also reduced (by $56 \%$ in both men and women) the magnitude of DCM incidence. ${ }^{147}$

Cigarette smoking is an obvious and important modifiable risk factor for cardiovascular disease. Smoking cessation confers immediate and lasting benefits that are likely to be even greater in people with diabetes, whose vascular risk is further increased by smoking. In the Multiple Risk Factor Intervention Study (MRFIT), the absolute risk of cardiovascular death over 12 years was much higher for diabetes subjects compared with the nondiabetes participants 
and was significantly associated with reported number of cigarettes/day $(P<0.0001)$. Together with dyslipidemia and hypertension, cigarette smoking was a dominant predictor of cardiovascular morbidity (increased risk for DCM by 53\% in both sexes) and cardiovascular mortality (overall 3 times higher risk of death from heart failure). ${ }^{103,148}$

\section{Optimizing glycemic control}

This is an important treatment aim in the management of DCM. A prospective cohort study analyzed the relative risk of macrovascular disease in patients with newly diagnosed type 2 diabetes and determined whether an intensive approach to dietary management, besides satisfactory glycemic control, would ameliorate the long-term cardiovascular risk and reduce the incidence of DCM and cardiovascular mortality. The study compared dietary management alone to oral hypoglycemic therapy (tolbutamide $500 \mathrm{mg}$ or metformin twice a day) with continued diet and finally insulin regimen. At the end of the 10-year follow-up period, the survival rate was $75 \%$, whereas $26 \%$ of the patients suffered myocardial infarction, of which $41 \%$ was fatal. The analysis of baseline data showed a relative risk equal to 1.04 for myocardial infarction for each $1 \mathrm{mmol} / \mathrm{L}$ increase in fasting plasma glucose. The risk of myocardial infarction while on insulin or oral treatment was not significantly elevated relative to dietary treatment. The study concluded that fasting plasma glucose is a significantly independent predictor of diabetic macrovascular disease, and the type of antidiabetic treatment does not prevent long-term cardiovascular disease. ${ }^{149}$

The epidemiological analysis of a prospective, multicenter, population-based study of patients with newly diagnosed type 2 diabetes demonstrated that the incidence of myocardial infarction was $15.2 \%$ and of these $19.2 \%$ died. The results showed that good glycemic control was associated with lower risk not only for myocardial infarction (15.2\% vs $42 \%$ ) but also for DCM (15\% vs 32\%). Good glycemic control was associated with a lower incidence of DCM (27\% vs 9\%), whereas postprandial blood glucose levels were among the independent predictors for cardiovascular morbidity and mortality. ${ }^{150,151}$ The UKPDS evaluated the relationship between exposure to glycemia over time and the development of DCM in patients with type 2 diabetes. For each $1 \%$ reduction in mean $\mathrm{HbA}_{1 \mathrm{c}}$, there was a $14 \%$ associated decrease in risk for myocardial infarction and a $16 \%$ decrease in risk for heart failure. ${ }^{152}$

\section{Management of dyslipidemia}

A double-blind, randomized, placebo-controlled, multicenter clinical trial assessed the effect of cholesterol lowering with simvastatin on mortality and the risk of coronary heart disease in patients with diabetes and DCM. Treatment of dyslipidemia significantly decreased the risk of coronary heart disease (recurrent myocardial infarction) by 55\% $(P=0.002)$ in subjects with type 2 diabetes. Since in diabetes subjects with DCM the case fatality is very high, aggressive lipid lowering should be extended to diabetes subjects who have not yet experienced a clinical event (primary and secondary prevention). ${ }^{153}$

Another multicenter, randomized, double-blind, placebocontrolled study determined if treatment with gemfibrozil would reduce the incidence of major cardiovascular events and outcomes in patients with type 2 diabetes. DCM was reduced by $22 \%$ with gemfibrozil treatment, and major cardiovascular events were reduced by $24 \%$. For every $5 \mathrm{mg} / \mathrm{dL}$ increase in HDL cholesterol, there was an $11 \%$ reduction in cardiovascular events. ${ }^{154}$ The effect of lipidlowering treatment at various levels of glucose tolerance or hyperinsulinemia was also evaluated by the same group, and the association between diabetes status, glucose-insulin levels and cardiovascular risk was examined. In patients with diabetes, a fasting plasma insulin level $\geq 271 \mathrm{pmol} / \mathrm{L}$ was associated with a $31 \%$ increased risk of cardiovascular events. Gemfibrozil was effective in patients with diabetes, and the reduction in DCM was 53\%, whereas in cardiovascular mortality, it was $41 \% .^{155-157}$

\section{Hypertension management and renoprotection}

A randomized, double-blind, active-controlled clinical trial reached to determine whether the combined incidence of fatal coronary heart disease and nonfatal myocardial infarction differs between diuretic treatment (chlorthalidone) and 3 alternative therapies: calcium channel blockers (amlodipine), ACE inhibitors (lisinopril), and $\alpha$-blockers (doxazosin). The incidence of DCM was higher in the group under therapy with $\alpha$-blockers compared with diuretics (relative risk equal to 1.25 at a 4 -year rate). No significant differences were observed between calcium channel blockers, ACE inhibitors, and diuretics for the primary outcome or for all-cause mortality. Amlodipine had a higher 6-year rate of heart failure (10.2\% vs the diuretic group) and of hospitalized or fatal heart failure $(8.4 \%)$. Lisinopril was associated with a $10 \%$ higher risk of DCM and a $19 \%$ higher risk for heart failure. Five-year systolic blood pressure was significantly higher in the amlodipine group $(0.8 \mathrm{~mm} \mathrm{Hg}$; $P=0.03)$, and lisinopril $(2 \mathrm{~mm} \mathrm{Hg} ; P<0.001)$ groups, compared with chlorthalidone. Thus, thiazide-type diuretics 
should be considered first for antihypertensive treatment and for patients who cannot be treated with diuretics; calcium channel blockers and ACE inhibitors could be considered as alternative choices. ${ }^{158}$

A double-blind, randomized, $2 \times 2$ factorial study, the Heart Outcomes Prevention Evaluation (HOPE) study, compared an ACE inhibitor, ie, ramipril, vs placebo in preventing death from cardiovascular causes, myocardial infarction, or all-cause death. The study concluded that ramipril significantly reduced the rates of death (6.1\% compared with $8.1 \%$ in the placebo group), myocardial infarction (9.9\% vs $12.3 \%)$, and all-cause mortality (10.4\% vs $12.2 \%)$. Moreover, ramipril therapy significantly decreased the rate of heart failure $(9 \%$ vs $11.5 \%$ in the placebo group) and of DCM (6.4\% vs $7.6 \%$; $P=0.03$ ). Ramipril achieved a significant reduction in the new cases with diabetes in the high-risk population included in the study, with unknown myocardial dysfunction (low ejection fraction) or heart failure. ${ }^{159}$

The association between major cardiovascular events and the achievement of different blood pressure targets during antihypertensive therapy, as well as the addition of low doses of acetylsalicylic acid was assessed in another randomized trial. Felodipine $(5 \mathrm{mg} / \mathrm{d})$ was given as baseline therapy, and other agents were added according to a 5-step regimen. The lowest incidence of DCM and major cardiovascular morbidity and mortality occurred in the blood pressure target group of $\leq 135 / 80 \mathrm{~mm} \mathrm{Hg}$. DCM was reduced by $51 \%$, and the addition of acetylsalicylic acid further achieved a $15 \%$ reduction in major cardiovascular morbidity and a $36 \%$ reduction in myocardial infarction. The study demonstrated that active lowering of blood pressure is particularly beneficial in patients with diabetes and that addition of a small dose of acetylsalicylic acid, provided that blood pressure is well controlled and the risk of gastrointestinal and nasal bleeding is carefully assessed, further reduces the risk of acute myocardial infarction. ${ }^{160}$

A double-masked, randomized, parallel-controlled group trial determined the effectiveness of losartan, a selective angiotensin II type 1 (AT1) receptor antagonist in comparison with the $\beta$-blocker atenolol in reducing cardiovascular morbidity and mortality in diabetes patients with hypertension and LV hypertrophy. Losartan was more effective than atenolol in reducing cardiovascular morbidity and mortality $(76 \%$ reduction of the relative risk of a primary cardiovascular end point). The greater cardiovascular protection of losartan was attributed mainly to the result of a more pronounced protection against the detrimental effects of angiotensin II. ${ }^{161}$

A randomized controlled trial, further determined the effectiveness of tight blood pressure control $(<150 / 85 \mathrm{~mm} \mathrm{Hg})$ with the use of an ACE inhibitor (captopril) or a $\beta$-blocker (atenolol) as main treatment in the reduction of cardiovascular morbidity and mortality. Reduction in cardiovascular risk by $24 \%$ in all end points related to diabetes was achieved with tight blood pressure control ( $32 \%$ in deaths). In addition, there was a $56 \%$ reduction in the risk of heart failure. ${ }^{162}$

Microalbuminuria heralds a further increase in risk of myocardial infarction and necessitates even stricter blood pressure control. A randomized control trial determined that blood pressure lowering with captopril and atenolol is equally effective and safe in reducing the risk of fatal and nonfatal macrovascular and microvascular complications in patients with type 2 diabetes. ${ }^{163}$ ACE inhibitors largely remain in the antihypertensive class of choice, as their use delays the progression of nephropathy. ${ }^{164}$

\section{Medical management of cardiovascular disease in diabetes}

Heart failure is also conventionally managed with diuretics and ACE inhibitors. Certain $\beta$-blockers, such as carvedilol, are among the drugs of choice for patients with diabetes, due to the fact that it has a beneficial effect on insulin resistance and a neutral activity on the lipid profile of patients with diabetes. ${ }^{165,166}$ The results of the intervention studies for the prevention of DCM are summarized in Table 2.

\section{Struggling toward additional knowledge \\ Targeting the pathophysiological substrate: new experimental therapies, regimens, and remedies}

Recently, direct correlations between apelin plasma levels and the structural and functional alterations, ie, LV hypertrophy and pressure overload, were demonstrated in humans and diabetic rats with DCM. A parallel study was conducted in streptozotocin-induced diabetic rats, where pressure overload was established by suprarenal aortic banding, as well as in patients with diabetes, where during surgery for aortic and mitral stenosis, LV function and structure were evaluated by $2 \mathrm{DE}$ and $\mathrm{LV}$ endomyocardial biopsies were procured. In both situations, the myocardial expression of apelin was significantly downregulated by pressure overload and apelin plasma levels were accordingly elevated. Since activation of the apelinergic system has a direct positive inotropic and vasodilatation effect, it was concluded that elevation in apelin 
Table 2 Major studies on treatment strategies of diabetic cardiomyopathy

\begin{tabular}{|c|c|c|c|c|c|c|}
\hline Reference & $\begin{array}{l}\text { Type } \\
\text { of diabetes }\end{array}$ & Intervention & Purpose & $\begin{array}{l}\text { Follow-up } \\
\text { period }\end{array}$ & Treatment regimen & Results \\
\hline [145] & 2 & Diet/exercise & $\begin{array}{l}\downarrow \text { incidence } \\
\text { of DCM }\end{array}$ & $6 y$ & $\begin{array}{l}\text { Control }(n=195) \\
\text { vs exercise }(n=211) \\
\text { vs diet }+ \text { exercise }(n=194)\end{array}$ & $\begin{array}{l}33 \% \downarrow \text { in the diet group } \\
47 \% \downarrow \text { in the exercise group } \\
38 \% \downarrow \text { in the diet }+ \text { exercise }\end{array}$ \\
\hline$[146,147]$ & $2 / I G T$ & $\begin{array}{l}\text { Behavioral diet + } \\
\text { physical therapy }\end{array}$ & $\begin{array}{l}\downarrow \text { onset of diabetes } \\
\downarrow \text { DCM incidence }\end{array}$ & $3.2 y$ & $\begin{array}{l}\text { Individualized counseling } \\
\text { vs general oral and written } \\
\text { information about diet/ } \\
\text { exercise }\end{array}$ & $\begin{array}{l}58 \% \downarrow \text { in the intervention } \\
\text { group of diabetes } \\
56 \% \downarrow \text { in the intervention } \\
\text { group of DCM }\end{array}$ \\
\hline [149] & $\begin{array}{l}2, \text { newly } \\
\text { diagnosed }\end{array}$ & $\begin{array}{l}\text { Prolonged dietary } \\
\text { management }\end{array}$ & $\begin{array}{l}\downarrow \text { DCM incidence } \\
\downarrow \text { of cardiovascular } \\
\text { mortality }\end{array}$ & $10 y$ & $\begin{array}{l}\text { Diet alone }(n=219) \text { vs } \\
\text { diet }+ \text { tolbutamide } \\
500 \mathrm{mg} / \text { metformin } \\
\text { twice a day }(n=140) \text { vs } \\
\text { insulin }(n=73)\end{array}$ & $\begin{array}{l}\text { I.04 RR for Ml per } \\
\uparrow ~ I ~ m m o l / L \text { in fasting plasma } \\
\text { glucose, no difference } \\
\text { between treatments for } \\
\text { the risk of } \mathrm{Ml}\end{array}$ \\
\hline$[150]$ & $\begin{array}{l}2, \text { newly } \\
\text { diagnosed }\end{array}$ & $\begin{array}{l}\text { Intensified health } \\
\text { education }\end{array}$ & $\begin{array}{l}\downarrow \text { MI incidence } \\
\downarrow \text { all-cause } \\
\text { mortality }\end{array}$ & $11 y$ & $\begin{array}{l}\text { a. Usual care }(n=378) \text { vs } \\
\text { b. intensified health } \\
\text { education }(n=334) \\
\text { vs b }+1.6 \text { clofibric } \\
\text { acid/day }(n=332)\end{array}$ & $\begin{array}{l}\text { I5.2\% patients suffered } \\
\text { from MI and } 19.2 \% \text { died, } \\
\text { postprandial glucose levels } \\
\text { were independent risk } \\
\text { factors for CVD death }\end{array}$ \\
\hline [152] & 2 & none & $\begin{array}{l}\text { Evaluation of } \\
\text { hyperglycemia } \\
\text { exposure to the } \\
\text { incidence of DCM }\end{array}$ & $10 y$ & Not applicable & $\begin{array}{l}\text { Each } 1 \% \downarrow \text { in } \mathrm{HbA}_{\mathrm{Ic}} \text { was } \\
\text { associated with: } \\
14 \% \downarrow \text { in risk for } \mathrm{MI} \\
16 \% \downarrow \text { in risk for } \mathrm{HF}\end{array}$ \\
\hline [153] & 2 & $\begin{array}{l}\text { Simvastatin } \\
20 \text { to } 40 \mathrm{mg}\end{array}$ & $\begin{array}{l}\text { Prevention of } \\
\text { recurrent CVD } \\
\text { in DCM }\end{array}$ & $5.4 y$ & $\begin{array}{l}\text { Placebo vs simvastatin } \\
20 \text { to } 40 \mathrm{mg} \text { per day }\end{array}$ & $55 \% \downarrow$ in CVD risk \\
\hline$[154]$ & 2 & $\begin{array}{l}\text { Gemfibrozil } \\
\text { I,200 mg/day }\end{array}$ & $\begin{array}{l}\text { Changes in plasma } \\
\text { lipids could reduce } \\
\text { major CVD events }\end{array}$ & $7 y$ & $\begin{array}{l}\text { Placebo }(n=1.267) \\
\text { vs gemfibrozil } \\
\text { I,200 mg/day } \\
(n=1.264)\end{array}$ & $\begin{array}{l}22 \% \downarrow \text { of CVD events for } \\
\text { every } 5 \mathrm{mg} / \mathrm{dL} \uparrow \text { in HDL-C, } \\
\text { there was an II\% } \downarrow \text { in CVD } \\
\text { events }\end{array}$ \\
\hline$[155]$ & 2 & $\begin{array}{l}\text { Gemfibrozil } \\
\text { I,200 mg/day }\end{array}$ & $\begin{array}{l}\text { Efficacy of } \\
\text { gemfibrozil in } \\
\text { varying glucose } \\
\text { levels association } \\
\text { between } \\
\text { hyperglycemia } \\
\text { and CVD risk }\end{array}$ & $7 y$ & $\begin{array}{l}\text { Placebo }(n=1.267) \\
\text { vs gemfibrozil } \\
\text { I,200 mg/day } \\
(n=1.264)\end{array}$ & $\begin{array}{l}\text { Fasting insulin } \geq 271 \mathrm{pmol} / \mathrm{L} \\
\text { was associated with: } \\
31 \% \uparrow \mathrm{CVD} \text { risk } \\
41 \% \downarrow \text { in CVD death }\end{array}$ \\
\hline [158] & 2 & $\begin{array}{l}\text { Diuretic or } \\
\text { Ca-blocker or ACE }\end{array}$ & $\begin{array}{l}\text { Differences in } \\
\text { CVD risk between } \\
\text { antihypertensive } \\
\text { regiments }\end{array}$ & $4.9 y$ & $\begin{array}{l}\text { Diuretic (chlorthalidone } \\
\text { I } 2.5 \text { to } 25 \mathrm{md} / \mathrm{d}, \mathrm{n}=15.255 \text { ) } \\
\text { or Ca-blocker (amlodipine } \\
2.5 \text { to } 10 \mathrm{mg} / \mathrm{d}, \mathrm{n}=9.048 \text { ), } \\
\text { or ACE inhibitor (lisinopril } \\
10 \text { to } 40 \mathrm{mg} / \mathrm{d}, \mathrm{n}=9.054 \text { ) }\end{array}$ & $\begin{array}{l}10.2 \% \uparrow \text { risk of HF with } \\
\text { amlodipine } \\
19 \% \uparrow \text { risk of HF with } \\
\text { lisinopril } \\
33.3 \% \uparrow \text { risk of DCM with } \\
\text { lisinopril, better blood } \\
\text { pressure control with } \\
\text { chlorthalidone }\end{array}$ \\
\hline [159] & 2 & $\begin{array}{l}\text { Ramipril } \\
10 \mathrm{mg} / \text { day }\end{array}$ & $\begin{array}{l}\text { Prevention death } \\
\text { from CVD, MI, all- } \\
\text { cause mortality, HF, } \\
\text { DCM, development } \\
\text { of diabetes }\end{array}$ & $5 y$ & $\begin{array}{l}\text { Placebo }(n=4.652) \text { vs } \\
\text { ramipril }(n=4.645)\end{array}$ & $\begin{array}{l}\text { 6.1\% } \downarrow \text { of CVD death } \\
9.9 \% \downarrow \text { of MI } \\
10.4 \% \downarrow \text { of all-cause death } \\
9 \% \downarrow \text { of HF } \\
6.4 \% \downarrow \text { of DCM } \\
3.6 \% \downarrow \text { in new diabetes }\end{array}$ \\
\hline$[160]$ & 2 & $\begin{array}{l}\text { Felodipine } \\
5 \mathrm{mg} / \text { day }\end{array}$ & $\begin{array}{l}\text { Achievement of } \\
\text { blood pressure } \\
\text { targets with the } \\
\text { addition of ASA } \\
\text { and association to } \\
\text { DCM and CVD risk }\end{array}$ & $3.8 y$ & $\begin{array}{l}\text { Felodipine } 5 \mathrm{mg} / \mathrm{d}+ \\
\text { ASA vs felodipine } \\
5 \mathrm{mg} / \mathrm{d}+\text { placebo }\end{array}$ & $\begin{array}{l}51 \% \downarrow \text { of CVD risk in target } \\
\leq 135 / 80 \mathrm{~mm} \mathrm{Hg}+ \\
15 \% \downarrow \text { of CVD risk with } \\
\text { ASA and } 36 \% \downarrow \text { in MI }\end{array}$ \\
\hline
\end{tabular}


Table 2 (Continued)

\begin{tabular}{|c|c|c|c|c|c|c|}
\hline Reference & $\begin{array}{l}\text { Type } \\
\text { of diabetes }\end{array}$ & Intervention & Purpose & $\begin{array}{l}\text { Follow-up } \\
\text { period }\end{array}$ & Treatment regimen & Results \\
\hline$[161]$ & 2 & $\begin{array}{l}\text { Losartan } \\
50 \text { to } 100 \mathrm{mg} / \mathrm{d}\end{array}$ & $\begin{array}{l}\downarrow \text { of CVD risk with } \\
\text { losartan vs } \\
\text { atenolol }\end{array}$ & $4.7 y$ & $\begin{array}{l}\text { Losartan } 50-100 \mathrm{mg} / \mathrm{d} \\
(\mathrm{n}=586) \mathrm{vs} \text { atenolol } \\
50-100 \mathrm{mg} / \mathrm{d}(\mathrm{n}=609)\end{array}$ & $76 \% \downarrow$ of relative CVD risk \\
\hline [162] & 2 & $\begin{array}{l}\text { Blood pressure } \\
\text { control } \\
<150 / 80 \mathrm{~mm} \mathrm{Hg}\end{array}$ & $\downarrow$ of CVD risk & $8.4 y$ & $\begin{array}{l}\text { Captopril }(50-100 \mathrm{mg} / \mathrm{d} \\
\mathrm{n}=400) \text { vs atenolol } \\
(50-100 \mathrm{mg} / \mathrm{d}, \mathrm{n}=358)\end{array}$ & $\begin{array}{l}24 \% \downarrow \text { of CVD risk } \\
32 \% \downarrow \text { of death } \\
56 \% \downarrow \text { of HF }\end{array}$ \\
\hline [164] & 2 & $\begin{array}{l}\text { Irbesartan } 300 \mathrm{mg} / \mathrm{d} \text { vs } \\
\text { amlodipine } 10 \mathrm{mg} / \mathrm{d}\end{array}$ & $\begin{array}{l}\downarrow \text { of blood pressure } \\
\text { provides protection } \\
\text { against progression } \\
\text { of nephropathy }\end{array}$ & $2.6 \mathrm{y}$ & $\begin{array}{l}\text { Irbesartan ( } 300 \mathrm{mg} / \mathrm{d} \text {, } \\
\mathrm{n}=579) \text { vs amlodipine } \\
(10 \mathrm{mg} / \mathrm{d}, \mathrm{n}=567) \\
\text { vs placebo }\end{array}$ & $\begin{array}{l}\text { With irbesartan: } \\
37 \% \downarrow \text { risk of doubling } \\
\text { serum creatinine } \\
23 \% \downarrow \text { risk of end-stage } \\
\text { renal disease } \\
23 \% \downarrow \text { risk of HF }\end{array}$ \\
\hline [166] & 2 & $\begin{array}{l}\text { Clopidogrel } 300 \mathrm{mg} / \mathrm{d} \\
\text { bolus, followed by } \\
\text { clopidogrel } 75 \mathrm{mg} / \mathrm{d} \\
\text { for } 3-12 \mathrm{mo}\end{array}$ & $\downarrow$ of CVD mortality & Iy & $\begin{array}{l}\text { Clopidogrel } 300 \mathrm{mg} / \mathrm{d} \\
\text { bolus, followed by } \\
\text { clopidogrel } 75 \mathrm{mg} / \mathrm{d} \\
\text { for } 3-12 \mathrm{mo} \text { vs placebo }\end{array}$ & $15 \% \downarrow$ of MI rate \\
\hline
\end{tabular}

Abbreviations: DCM, diabetic cardiomyopathy; IGT, impaired glucose tolerance; RR, relative risk; MI, myocardial infarction; CVD, cardiovascular disease death; HF, heart failure; HDL-C, high density lipoprotein-cholesterol levels; Ca-blocker, calcium channel blocker; ACE, angiotensin-converting-enzyme; ASA, acetylsalicylic acid.

plasma levels may represent a compensatory mechanism to maintain inotropism and cardiac output during pressure overload conditions, such as DCM. ${ }^{167}$

The kinins are vasoactive peptides and part of the kallikrein-kinin system (KKS). Recent studies have demonstrated that they are involved in different aspects of remodeling, inflammation, and angiogenesis. It is increasingly recognized that the KKS is involved in the inflammatory processes of the heart. Evidence shows that the KKS has beneficial effects in myocardial diseases by protecting from inflammation, fibrosis, and apoptosis. KKS also shows a proinflammatory character by increasing the production of cytokines and stimulating the migration of immune cells. Novel important actions of the KKS contribute to neovascularization and recruitment of endothelial progenitor cells in ischemic areas and endothelial dysfunction. All these evidence support that the KKS could constitute a potential therapeutic target in the treatment of myocardial ischemia and DCM. ${ }^{168}$

As previously discussed, ${ }^{47}$ a significant role in the myocardial dysfunction of DCM is supported by the reduction of the sarcoplasmic calcium ATPase myocardial expression (SERCA2). Resveratrol, a potent activator of the cardiac function and the SERCA2 in type 1 diabetes were recently administered to adult male streptozotocin-induced diabetic mice, where the induced diabetes produced a progressive decline in cardiac function associated with markedly reduced SERCA2 and increased collagen deposition. Resveratrol treatment to these mice had a tremendous beneficial effect both in terms of improving SERCA2 expression and cardiac function.
The data demonstrate that in DCM, where the expression of SERCA2 is reduced, resveratrol enhances the expression of the SERCA2 and improves cardiac function. ${ }^{169}$

Cardiac fibrosis and protein O-glycosylation are elevated in $\mathrm{DCM}^{22,23}$ One in vitro study in rat cardiac fibroblasts recently demonstrated that long-term glucose load significantly increases collagen expression. Treatment with glucosamine not only induced the collagen expression but also increased the O-glycosylated protein. These results suggest that O-glycosylation of protein modifies collagen expression and, therefore, contributes to DCM. ${ }^{170}$ ROSs play an important role in the development of DCM..$^{42,43}$ Matrix metalloproteinase 2 (MMP-2) is activated by ROS and contributes to the acute loss of myocardial contractile function by targeting and cleaving susceptible proteins including troponin I and $\alpha$-actinin. Using the streptozotocin-induced diabetic rat model, one study evaluated the 4-week administration effect on heart function of a daily in vivo administration of sodium selenate $(0.3 \mathrm{mg} / \mathrm{kg})$ or a pure $\omega-3$ fish oil with antioxidant vitamin $\mathrm{E}(\omega-3 \mathrm{E}, 50 \mathrm{mg} / \mathrm{kg})$. Both treatments prevented the diabetes-induced functional changes; however, the improvement in myocardial function was greater with sodium selenate compared with that of the omega-3E. Moreover, these treatments reduced the diabetes-induced increase in myocardial oxidized protein sulfhydryl and nitrite concentrations. The diabetes-induced changes in myocardial levels of MMP-2 were associated with a significant reduction in troponin I and $\alpha$-actinin protein levels in both treatment groups. These results suggest that diabetes-induced alterations in MMP-2 contribute to myocardial contractile dysfunction by targeting 
troponin I and $\alpha$-actinin and that sodium selenate or omega-3E could have therapeutic benefits in DCM. ${ }^{171}$

Another study also aimed at the suppression of mitochondrial oxidative stress and mitochondrion-dependent myocardial apoptosis with the administration of antioxidant $\alpha$-lipoic acid ( $\alpha$-LA) to prevent evolution of DCM. In a streptozotocin-induced diabetic rat model, $\alpha$-LA was administered (100 mg/kg intraperitoneally per day) for 12 weeks. Antioxidant $\alpha$-LA effectively attenuated mitochondriondependent cardiac apoptosis and exerted a protective role against the development of DCM. The ability of $\alpha$-LA to suppress mitochondrial oxidative damage was concomitant with an enhancement of manganese superoxide dismutase activity in the myocardial mitochondria and an increase in the glutathione content of myocardial mitochondria. ${ }^{172}$

The diabetic heart is resistant to ischemic preconditioning because of diabetes-associated impairment of phosphatidylinositol 3-kinase (PI3K)-Akt signaling. One study examined the hypothesis that phosphorylation of Janus kinase 2 (Jak2) upstream of PI3K is impaired in diabetic hearts by an AT1 receptor-mediated mechanism. Thus, in a type 2 diabetic rat model, myocardial infarct was produced. Erythropoietin (EPO) administration activated the Jak2-mediated signaling and limited the infarct size in experimental rats. Where EPO failed to induced infarct size limitation, blockade of the AT1 receptor by valsartan or losartan treatment for 2 weeks restored the myocardial response to EPO. Furthermore, treatment with valsartan normalized the calcineurin activity in diabetic rats. These results suggest that the diabetic heart is refractory to protection by Jak2-activating ligands because of AT1 receptor-mediated upregulation of calcineurin activity. ${ }^{173}$

The $\beta$ isoform of protein kinase $C(P K C-\beta)$ is a target implicated in diabetic complications. To investigate the influence of breviscapine on the cardiac structure and function in rats with DCM, as well as the expression of PKC and $\mathrm{Ca}^{2+}$ cycling proteins, type 2 diabetic rats were treated with breviscapine for 6 weeks, and invasive cardiac function and echocardiographic parameters were measured, while heart tissue was obtained for electron microscope study. Treatment with breviscapine reversed the cardiac dysfunction and structure changes in rats with DCM, decreased the expression of PKC, and increased the expression of calcium handling regulators, ie, protein phosphatase inhibitor-1, phospholamban, and SERCA2. This study showed that breviscapine has a protective effect on DCM, which is dose related. ${ }^{174}$ Breviscapine also prevented cardiac hypertrophy in diabetic rats by inhibiting the expression of $\mathrm{PKC}$, which may have a protective effect in the pathogenesis of DCM via the $\mathrm{PKC}$ / $\mathrm{NF}-\kappa \mathrm{B} / \mathrm{c}$-fos signal transduction pathway. ${ }^{175}$

Using a hemodynamically validated rodent model of diabetic diastolic heart failure, the (mRen-2)27 transgenic rat another study further determined the selective inhibition of PKC- $\beta$. Preservation of cardiac function and reduction of structural injury were evaluated. Diabetic rats were randomized to receive either vehicle or the PKC- $\beta$ inhibitor, ruboxistaurin $(20 \mathrm{mg} / \mathrm{kg} /$ day) and followed for 6 weeks. Compared with untreated animals, ruboxistaurin-treated diabetic rats demonstrated preserved systolic and diastolic function. Collagen deposition and cardiomyocyte hypertrophy were both reduced in diabetic animals treated with ruboxistaurin as was phosphorylated-Smad2, an index of transforming growth factor $\beta$ (TGF- $\beta$ ) activity. PKC- $\beta$ inhibition attenuated diastolic dysfunction, myocyte hypertrophy, and collagen deposition and preserved cardiac contractility. PKC- $\beta$ inhibition may represent a novel therapeutic strategy for the prevention of diabetes-associated cardiac dysfunction. ${ }^{176}$

Studies have shown that caffeic and ellagic acid, 2 phenolic acids naturally occurring in many plant foods, can provide triglyceride-lowering, anticoagulatory, antioxidative, and anti-inflammatory protection in cardiac tissue of diabetic mice. Thus, the supplement of these agents might be helpful for the prevention or attenuation of DCM. ${ }^{177}$

Total aralosides of Aralia elata (Miq) Seem (TASAES) from the Chinese traditional herb Longya Aralia chinensis L. has been demonstrated to improve cardiac function. A recent study determined the protective effects of TASAES on DCM in streptozotocin-induced diabetic rats. Diabetic rats were treated with TASAES for 8 weeks. Cardiac function was evaluated by in situ hemodynamic measurements. TASAES showed a significant protection against diabetes-induced cardiac dysfunction and enhanced the amplitude of $\mathrm{Ca}^{2+}$ channel currents. Moreover, histological staining indicated a significant inhibition of diabetes-caused pathological changes and upregulation of profibrotic factor, and connective tissue growth factor, and expression. The results suggest that TASAES prevents diabetes-induced cardiac dysfunction and pathological damage. ${ }^{178}$

The effects of Ginkgo biloba extract (EGb 761), a radical scavenger, against diabetes-induced myocardial interstitium and microvasculature damage and against additional ischemia or reperfusion injury in spontaneously diabetic BioBreeding/ Ottawa Karlsburg $(\mathrm{BB} / \mathrm{OK})$ rats modeling diabetic cardiac infarction were also investigated as an alternative antioxidative therapy. Pretreatment of diabetic myocardium with EGb resulted in an improvement of impaired endothe- 
lial-dependent vasodilatation in diabetes and additional ischemia or reperfusion, diminished mast cell and substance $P$ accumulation, and better preserved myocardial ultrastructure compared with unprotected myocardium. EGb may act as a potent therapeutic adjuvant in patients with diabetes with respect to ischemic myocardial injury and may contribute to preventing late complications in DCM. ${ }^{179}$ Another study, also demonstrated $\mathrm{EGb}$ as a promising adjuvant therapeutic drug in patients with diabetes with respect to ischemic myocardium injury. It concluded that it may contribute to the prevention of late diabetic complications in DCM. ${ }^{180}$

Natural medicine for the treatment of DCM was further recognized by the demonstration of grape seed proanthocyanidin extracts (GSPEs) as therapeutic agents against DCM in streptozotocin-induced diabetic rats. GSPEs decreased AGEs and ameliorated glycation-associated cardiac damage. ${ }^{181}$

Recent studies in mice experimental models with acute ischemic injury revealed that EPO has numerous tissueprotective effects in the heart, brain, and kidneys. One study explored the tissue-protective properties of chronic EPO treatment in an experimental model of the $\mathrm{db} / \mathrm{db}$ mouse with diabetic heart injury. Continuous erythropoietin receptor activator (CERA)-treated mice had a significant reduction in TGF- $\beta 1$ and collagen I expression in cardiac tissue. Atrial natriuretic peptide expression was increased in CERA-treated mice. Chronic treatment with CERA protects cardiac tissue in diabetic animals by inhibiting molecular pathways of cardiac fibrosis, and the effects are dose dependent. ${ }^{182}$

\section{Cell-based myocardial regenerative therapy}

Cell-based myocardial regenerative therapy can be potentially applied in the treatment of DCM in order to limit the consequences of decreased contractile function and compliance of damaged ventricles, owing to ischemic and nonischemic myocardial areas. A variety of myogenic and angiogenic cell types have been proposed, such as skeletal myoblasts, mononuclear and mesenchymal bone marrow cells, circulating blood-derived progenitors, adipose-derived stromal cells, induced pluripotent stem cells, umbilical cord cells, endometrial mesenchymal stem cells, adult testis pluripotent stem cells, and embryonic cells. It is important to note that stem cells are not an alternative to heart transplantation; selected patients should be in an early stage of heart failure, as the goal of this regenerative approach is to avoid or delay organ transplantation. Since the cell niche provides crucial support needed for stem cell maintenance, the most interesting and realistic perspectives include the association of intramyocardial cell transplantation with tissue-engineered scaffolds and multisite cardiac pacing in order to transform a passive regenerative approach into a "dynamic cellular support," a promising method for the creation of "bioartificial myocardium". ${ }^{183}$

\section{Conclusion}

DCM is not uncommon and is associated with increased morbidity and mortality in patients with diabetes. Metabolic pathway deregulation in diabetes adversely affects the cardiac myocytes, as well as every cellular element within the vascular walls. Other pathogenetic mechanisms involved in decreasing myocardial contractility in DCM are impaired calcium homeostasis, renin-angiotensin system upregulation, increased oxidative stress, altered substrate metabolism, and mitochondrial dysfunction. ${ }^{184}$ Continued research has provided novel insights into underlying molecular and pathophysiological mechanisms that increase the vulnerability of the diabetic heart to failure. ${ }^{185}$ The choice of antidiabetic medication may influence the cardiovascular outcome. ${ }^{186,187}$ However, intensive treatment of the gamut of metabolic abnormalities associated with diabetes beyond hyperglycemia reduces the rates of DCM, myocardial infarction, and associated cardiovascular death. As this high-risk population increases, elucidation of the mechanisms responsible for DCM will further motivate the generation of novel therapies tailored to decrease the cardiovascular morbidity and mortality in diabetes. Strategies to encourage the aggressive use of targeted medical therapies will further reduce the magnified rates of the diabetic heart failure burden.

\section{Disclosure}

The authors report no conflicts of interest in this work.

\section{References}

1. Amos AF, McCarty DJ, Zimmet P. The rising global burden of diabetes and its complications: estimates and projections to the year 2010. Diabet Med. 1997;14 Suppl 1:S1-S85.

2. Fisher BM, Gillen G, Lindop GB, Dargie HJ, Frier BM. Cardiac function and coronary arteriography in asymptomatic type-1 (insulin-dependent) diabetic patients: evidence for a specific diabetic heart disease. Diabetologia. 1986;29:706-712.

3. Kannel WB, Hjortland M, Castelli WP. Role of diabetes in congestive heart failure: the Framingham Study. Am J Cardiol. 1976;34:29-34.

4. Kannel WB, McGee DL. Diabetes and cardiovascular disease: the Framingham Study. JAMA. 1979;241:2035-2038.

5. Rubler S, Dlugash J, Yuceoglu YZ, Kumral T, Branwood AW, Grishman A. New type of cardiomyopathy associated with diabetic glomerulosclerosis. Am J Cardiol. 1972;30:595-602.

6. Zimmet P, Alberti KG MM, Swan J. Global and social implications of the diabetes epidemic. Nature. 2001;414:782-787. 
7. Berenson GS, Srinivasan SR, Bao W, Newman WP III, Tracy RE, Wattigney WA. Association between multiple cardiovascular risk factors and atherosclerosis in children and young adults. The Bogalusa Heart Study. N Engl J Med. 1998;338:1650-1656.

8. Kròlewski AS, Kosinski EJ, Warram JH, et al. Magnitude and determinants of coronary artery disease in juvenile-onset, insulindependent diabetes mellitus. Am J Cardiol. 1987;59:750-755.

9. Barrett-Connor E, Wingard DL. Sex differences in ischemic heart disease mortality in diabetics: a prospective population based study Am J Epidemiol. 1983;118:489-496.

10. Gaede P, Vedel P, Parving HH, Pedersen O. Intensified multifactorial intervention in patients with type 2 diabetes mellitus and microalbuminuria: the STENO type 2 randomized study. Lancet. 1999;353: 617-622.

11. Haffner SM, Lebto S, Roenemaa T, Pyörälä K, Laakso M. Mortality from coronary heart disease in subjects with type 2 diabetes and in non diabetic subjects with and without prior myocardial infarction. N Engl J Med. 1998;339:229-234.

12. Malmberg K, Ryden L. Myocardial infarction in patients with diabetes mellitus. Eur Heart J. 1988;9:256-264.

13. Herlitz J, Malmberg K, Karlsson B, Rydén L, Hjalmarson A. Mortality and morbidity during a five year follow up of diabetics with myocardial infarction. Acta Med Scand. 1988;24:31-38.

14. Norhammar A, Tenerz A, Nilsson G, et al. Glucose metabolism in patients with acute myocardial infarction and no previous diagnosis of diabetes mellitus: a prospective study. Lancet. 2002;359: 2140-2144.

15. Barzilay JI, Kronmal RA, Bittner V, Eaker E, Evans C, Foster ED. Coronary artery disease and coronary artery bypass grafting in diabetic subjects aged $\geq 65$ years. Am J Cardiol. 1994;74:334-339.

16. Borch-Johnsen K, Andersen PK, Deckert T. The effect of proteinuria on relative mortality in type-1 (insulin-dependent) diabetes mellitus. Diabetologia. 1985;28:590-596.

17. Bertoni AG, Tsai A, Kasper EK, Brancati FL. Diabetes and idiopathic cardiomyopathy. Diabetes Care. 2003;26:2791-2795.

18. Shindler DM, Kostis JB, Yusuf S, et al. Diabetes Mellitus, a predictor of morbidity and mortality in the studies of the left ventricular dysfunction (SOLVD) trials and registry. Am J Cardiol. 1996;77:1017-1020.

19. Ryden L, Armstrong PW, Cleland JG, et al. Efficacy and safety of highdose lisinopril in chronic heart failure patients at high cardiovascular risk, including those with diabetes mellitus. Results from the ATLAS trial. Eur Heart J. 2000;21:1967-1978.

20. Cohn JN, Johnson G, Ziesche S, et al. A comparison of enalapril with hydralazine-isosorbide dinitrate in the treatment of chronic congestive heart failure. N Engl J Med. 1991;325:303-310.

21. Hayat SA, Patel B, Khattar RS, Malik RA. Diabetic cardiomyopathy: mechanisms, diagnosis, and treatment. Clin Sci. 2004;107:539-557.

22. Vigorita VJ, Morre GW, Hutchens SM. Absence of correlation between coronary arterial atherosclerosis and severity or duration of diabetes mellitus of adult onset. Am J Cardiol. 1980;46:535-542.

23. Factor SM, Minase T, Sonnenblick EH. Clinical and morphological features of human hypertensive-diabetic cardiomyopathy. Am Heart J. 1980;99:446-458.

24. Factor SM, Bhan R, Minase T, Wolinsky H, Sonnenblick EH. Hypertensive diabetic cardiomyopathy in the rat: an experimental model of human disease. Am J Pathol. 1981;102:219-228.

25. Kawaguchi M, Techigawara M, Ishihata $\mathrm{T}$, et al. A comparison of ultrastructural changes on endomyocardial biopsy specimens obtained from patients with and without diabetes mellitus with and without hypertension. Heart Vessels. 1997;12:267-274.

26. Levy D, Garrison RJ, Savage DD, Kannel WB, Castelli WP. Prognostic implications of echocardiographically determined left ventricular mass in the Framingham Heart Study. $N$ Eng J Med. 1990;322: 1561-1566.

27. Palmieri V, Bella JN, Tracy RP. Relationship of left ventricular hypertrophy to inflammation and albuminuria in adults with type 2 diabetes. The Strong Heart Study. Diabetes Care. 2003;26:2764-2769.
28. Petrie MC, Caruana L, Berry C, McMurray JJ. Diastolic heart failure caused by subtle left ventricular systolic dysfunction? Heart. 2002; $87: 29-31$.

29. Brutsaert DL, Housmans PR, Goethals MA. Dual control of relaxation. Its role in the ventricular function in the mammalian heart. Circ Res. 1980;47:637-652.

30. Zile MR, Baicu CF, Gaasch WH. Diastolic heart failure: abnormalities in active relaxation and passive stiffness of the left ventricle. $N$ Engl J Med. 2004;350:1953-1959.

31. Raev DC. Which left ventricular dysfunction is impaired earlier in the evolution of diabetic cardiomyopathy? An echocardiographic study of young type 1 diabetic patients. Diabetes Care. 1994;17:633-639.

32. Riggs TW, Transue D. Doppler echocardiographic evaluation of left ventricular diastolic dysfunction in adolescents with diabetes mellitus. Am J Cardiol. 1990;65:899-902.

33. Margonato A, Gerundini P, Vicedomini G, Gilardi MC, Pozza G, Fazio F. Abnormal cardiovascular response to exercise in young asymptomatic diabetic patients with retinopathy. Am Heart J. 1986; 112:554-560.

34. Mirsky I. Assessing diastolic function: suggested methods and future considerations. Circulation. 1984;69:836-841.

35. Ommen SR, Nishimura RA. A clinical approach to the assessment of left ventricular diastolic function by Doppler echocardiography: update. Heart. 2003;89:18-23.

36. Aurigemma GP, Gottdiener JS, Shemanski L, Gardin J, Kitzman D. Predictive value of systolic and diastolic function for incident congestive heart failure in the elderly: the Cardiovascular Health Study. J Am Coll Cardiol. 2001;37:1042-1048.

37. Vasan R, Larson MG, Benjamin EJ, Evans JC, Reiss CK, Levy D. Congestive heart failure in subjects with normal versus reduced left ventricular ejection fraction: prevalence and mortality in a populationbased cohort. J Am Coll Cardiol. 1999;33:1948-1955.

38. Judge KW, Pawitan Y, Caldwell J, Gersh BJ, Kennedy JW. Congestive heart failure in patients with preserved left ventricular systolic function: analysis of the CASS registry. J Am Coll Cardiol. 1991;18:377-382.

39. Brogan WC III, Hillis LD, Flores ED, Lange RA. The natural history of isolated left ventricular diastolic dysfunction. Am J Med. 1992;92: 627-630.

40. Iribarren C, KarterAJ, Go AS. Glycaemic control and heart failure among adult patients with diabetes. Circulation. 2001;103:2668-2673.

41. Avendano GF, Agarwal RK, Bashey RI. Effects of glucose intolerance on myocardial function and collagen-linked glycation. Diabetes. 1999; 48:1443-1447.

42. Singh R, Barden A, Mori T, Beilin L. Advanced glycation end products: a review. Diabetologia. 2001;44:129-146.

43. Devereux RB, Roman MJ, Paranicas M. Impact of diabetes on cardiac structure and function: The Strong Heart Study. Circulation. 2000;101: 2271-2276.

44. Young ME, Mcnulty $P$ and Taegtmeyer H. Adaptation and maladaptation of the heart in Diabetes: part II Potential mechanisms. Circulation. 2002; 105:1861-1870.

45. Candido R, Forbes JM, Thomas MC. A breaker of advanced glycation end products attenuates diabetes induced myocardial structural changes. Circ Res. 2003;92:785-792.

46. Galderisi M, Anderson KM, Wilson PWF, Levy D. Echocardiographic evidence for the existence of a distinct diabetic cardiomyopathy. The Framingham Heart Study. Am J Cardiol. 1991;68:85-89.

47. Rodrigues B, Cam MC, McNeill JH. Metabolic disturbances in diabetic cardiomyopathy. Mol Cell Biochem. 1998;180:53-57.

48. Zhou Y, Grayburn P, Karim A. Lipotoxic heart disease in obese rats: implications for human obesity. Proc Natl Acad Sci U S A. 2000;97: 1794-1789.

49. Asif M, Egan J, Vasan S. An advanced gylcation end product crosslink breaker can reverse age-related increases in myocardial stiffness Proc Natl Acad Sci U S A. 2000;97:2809-2813.

50. Liang Q, Carlson EC, Donthi RV. Overexpression of metallothionein reduces diabetic cardiomyopathy. Diabetes. 2002;51:174-181. 
51. Zhang F, Li G, Ding W. Screening and analysis of early cardiopathologyrelated gene in type 2 diabetes mellitus. Zhonghua Nei Ke Za Zhi. 2002;41:530-533.

52. Monkemann H, de Vriese AS, Blom HJ. Early molecular events in the development of the diabetic cardiomyopathy. Amino Acids. 2002;23: 331-336.

53. Mizushige K, Yao L, Noma T, et al. Alteration in left ventricular diastolic filling and accumulation of myocardial collagen at insulinresistant prediabetic stage of type II diabetic model. Circulation. 2000;101:899-907.

54. Ren J, Sampson WK, Sowers JR. Insulin-like growth factor 1 as a cardiac hormon: physiological and pathophysiological implications in heart disease. Moll Cell Cardiol. 1999;31:2049-2061.

55. Airaksinen K, Kostinen J, Akaheimo M, Huikuri H. Augmentation of atrial contraction to LV filling in IDDM subjects as assessed by Doppler echocardiograph. Diabetes Care. 1989;12:159-161.

56. Ziegler D. Cardiovascular autonomic neuropathy: clinical manifestations and measurement. Diabetes Rev. 1999;7:300-315.

57. Kahn K, Zola B, Juni JE, Vinik AI. Radionuclide assessment of LV diastolic filling pressures in diabetes mellitus with and without cardiac autonomic neuropathy. J Am Coll Cardiol. 1986;7: 1303-1309.

58. Zola B, Kahn JK, Juni JE, Vinik AI. Abnormal cardiac function in diabetic patients with autonomic neuropathy in the absence of ischemic heart disease. J Clin Endocrinol Metab. 1986;63:208-214.

59. Uusitupa M, Mustonen J, Laakso M. Impairment of diastolic function in middle aged type 1 and type 2 diabetic patients free of cardiovascular disease. Diabetologia. 1988;31:783-791.

60. Rathmann W, Ziegler D, Jahnke M, Haastert B, Gries FA. Mortality in diabetic patients with cardiovascular autonomic neuropathy. Diabet Med. 1993;10:820-824.

61. Roy TM, Peterson HR, Snider HL, et al. Autonomic influence on cardiovascular performance in diabetic subjects. Am J Med. 1989;87: 382-388.

62. Annonu AK, Fattah AA, Mokhtar MS, Ghareeb S, Elhendy A. LV systolic and diastolic functional abnormalities in asymptomatic patients with non-insulin-dependent diabetes mellitus. J Am Soc Echocardiogr. 2001;14:885-891.

63. Mustonen J, Mantysaari M, Kuikka J. Decreased myocardial ${ }^{123} \mathrm{I}$-metaiodobenzylguanidine uptake is associated with disturbed LV diastolic filling in diabetes. Am Heart J. 1992;123:804-805.

64. Monteagudo PT, Moises VA, Kohlmann O Jr, Ribeiro AB, Lima VC, Zanella MT. Influence of autonomic neuropathy upon LV dysfunction in insulin-dependent diabetic patients. Clin Cardiol. 2000; 23:371-375

65. Willenheimer RB, Erhardt LR, Nilsson H, Lilja B, JuulMöller S, Sundkvist G. Parasympathetic neuropathy associated with left ventricular diastolic dysfunction in patients with insulin-dependent diabetes mellitus. Scand Cardiovasc J. 1998;32:17-22.

66. di Carli MF, Bianco-Batlles D, Landa ME. Effects of autonomic neuropathy on coronary blood flow in patients with diabetes mellitus. Circulation. 1999;100:813-819.

67. Balkau B, Jouven X, Ducimetiére P, Eschwège E. Diabetes as a risk factor for sudden death. Lancet. 1999;354:1968-1969.

68. Ewing DJ, Boland O, Neilson JM, Cho CG, Clarke BF. Autonomic neuropathy, QT interval lengthening, and unexpected deaths in male diabetic patients. Diabetologia. 1991;34:182-185.

69. Tentolouris N, Katsilambros N, Papazachos G, et al. Corrected QT interval in relation to the severity of diabetic autonomic neuropathy. Eur J Clin Invest. 1997;27:1049-1054.

70. Poirier P, Bogaty P, Philippon F, et al. Preclinical diabetic cardiomyopathy: relation of left ventricular diastolic dysfunction to cardiac autonomic neuropathy in men with uncomplicated well-controlled type 2 diabetes. Metabolism. 2003;52:1056-1061.

71. Voulgari C, Tentolouris N, Moyssakis I, et al. The spatial QRS-T angle is increased in patients with type 2 diabetes mellitus and cardiac autonomic neuropathy. Diabetologia. 2009;51 Suppl 1:S500-S500.
72. Chappet O, Dosquet C, Wautier MP, et al. Advanced glycation end products, oxidant stress and vascular lesions. Eur J Clin Invest. 1997; 27:97-108

73. Brownlee M. Advanced protein glycation in diabetes and aging. Ann Rev Med. 1995;46:223-234.

74. Ban CR, Twigg SM. Fibrosis in diabetes complications: pathogenic mechanisms and circulating and urinary markers. Vasc Health Risk Manag. 2008;4:575-596.

75. Effect of intensive management on macrovascular events and risk factors in Diabetes Control and Complications Trial. Am J Cardiol. 1995;75:894-903.

76. Stratton IM, Adler AI, Neil HA, et al. Association of glycaemia with macrovascular and microvascular complications in type 2 diabetes (UKPDS 35): prospective observational study. BMJ. 2000; 321:405-412.

77. Haffner SM. Impaired glucose tolerance, insulin resistance, and cardiovascular disease. Diabet Med. 1997;14 Suppl 3:S12-S18.

78. Despres JP, Lamarche B, Mauriege P, et al. Hyperinsulinemia as an independent risk factor for ischemic heart disease. $N$ Engl J Med. 1996;334:952-957.

79. Zavaroni I, Bonora E, Pagliara M, et al. Risk factors for coronary artery disease in healthy persons with hyperinsulinemia and normal glucose tolerance. $N$ Engl J Med. 1989;320:702-706.

80. Reaven GM. Banting lecture 1988. Role of insulin resistance in human disease. Diabetes. 1988;37:1595-1607.

81. Haffner SM, Mykkanen L, Festa A, et al. Insulin-resistant prediabetic subjects have more atherogenic risk factors than insulin-sensitive prediabetic subjects: implications for preventing coronary heart disease during the prediabetic stage. Circulation. 2000;101:975-980.

82. Koivisto VA, Stevens LK, Mattock M, et al. Cardiovascular disease and its risk factors in IDDM in Europe. EURODIAB IDDM Complications Study Group. Diabetes Care. 1996;19:689-697.

83. Kohler HP, Grant PJ. Mechanisms of disease: plasminogen activator inhibitor-1 and coronary artery disease. $N$ Engl J Med. 2000;342: 1792-1801.

84. Juhan-Vague I, Alessi MC, Vague P. Increased plasma plasminogen activator inhibitor 1 levels: a possible link between insulin resistance and atherothrombosis. Diabetologia. 1991;34:457-462.

85. Mansfield MW, Heywood D, Grant PJ. Circulating levels of factor VII, fibrinogen, and non Willebrand factor and features of insulin resistance in first degree relatives of patients with NIDDM. Circulation. 1996;94:2171-2176.

86. Heywood DM, Mansfield MW, Grant PJ. Factor VII gene polymorphisms, factor VII: C levels and features of insulin resistance in non-insulin-dependent diabetes mellitus. Thromb Haemost. 1996;75: 401-406.

87. Kohler HP, Carter AM, Stickland MH, Grant PJ. Levels of activated FXII in survivors of myocardial infarction: association with circulating risk factors and extent of coronary artery disease. Thromb Haemost. 1998;79:14-18.

88. Festa A, D’Agostino RJ, Howard G, Mykkänen L, Tracy RP, Haffner SM. Chronic subclinical inflammation as part of the insulin resistance syndrome: the Insulin Resistance Atherosclerosis Study (IRAS). Circulation. 2000;102:42-47

89. Schlkwijk CG, Poland DC, van Dijk W, et al. Plasma concentrations of C-reactive protein are increased in type 1 diabetic patients without clinical macroangiopathy and correlates with markers of endothelial dysfunction: evidence for chronic inflammation. Diabetologia. 1999;42:351-357.

90. Koenig W, Sund M, Frohlich M, et al. C-reactive protein, a sensitive marker of inflammation, predicts future risk of coronary heart disease in initially healthy middle-aged men: results from the MONICA (Monitoring Trends and Determinants in Cardiovascular Disease) Augsburg Cohort Study, 1984 to 1992. Circulation. 1999;99:237-242.

91. Ridker PM, Hennekens CH, Buring JE, Rifai N. C-reactive protein and other markers of inflammation in the prediction of cardiovascular disease in women. $N$ Engl J Med. 2000;342:836-843. 
92. Voulgari C, Tentolouris N, Papadogiannis D, et al. Increased left ventricular arrhythmogenicity in metabolic syndrome and relationship with myocardial performance, risk factors for atherosclerosis, and low-grade inflammation. Metabolism. 2010;59:159-165.

93. Feener EP, King GL. Vascular dysfunction in diabetes mellitus. Lancet. 1997;350:S19-S113

94. Zavaroni I, Dall'Aglio E, Bonora E, Alpi O, Passeri M, Reaven GM. Evidence that multiple risk factors for coronary artery disease exist in persons with abnormal glucose tolerance. Am J Med. 1987;83: 609-612.

95. Haffner SM, D’Agostino R Jr, Mykkanen L, et al. Insulin sensitivity in subjects with type 2 diabetes: relationship to cardiovascular risk factors. The insulin Resistance Atherosclerosis Study. Diabetes Care. 1999;22:562-568.

96. Grundy SM. Hypertriglyceridemia, atherogenic dyslipidemia and the metabolic syndrome. Am J Cardiol. 1988;81:18B-25B.

97. Austin MA, Edwards KL. Small dense low density lipoproteins, the insulin resistance syndrome, and non-insulin dependent diabetes. Curr Opin Lipidol. 1996;7:167-171.

98. Lamarche B, Tchernof A, Mauriege P, et al. Small, dense low-density lipoprotein particles as a predictor of the risk of ischemic heart disease in men. Prospective results from the Quebec Cardiovascular Study. Circulation. 1997;95:69-75.

99. Lamarche B, Tchernof A, Moorjani S, et al. Fasting insulin and apolipoprotein B levels and low-density lipoprotein particle size as risk factors for ischemic heart disease. JAMA. 1998;279:1955-1961.

100. Voulgari CH, Tentolouris N, Moyssakis I, et al. Spatial QRS-T angle: association with diabetes and left ventricular performance. Eur J Clin Invest. 2006;36:608-613.

101. Hiraga T, Kobayashi T, Okubo M, et al. Prospective study of lipoprotein (a) as a risk factor for atherosclerotic cardiovascular disease in patients with diabetes. Diabetes Care. 1995;18:241-244.

102. Forsblom CM, Sane T, Groop PH, et al. Risk factors for mortality in type II (non-insulin-dependent) diabetes: evidence for a role for neuropathy and a protective effect of HLA-DR4. Diabetologia. 1998; 41:1253-1262.

103. Stamler J, Vaccaro O, Neaton JD, et al. Diabetes, other risk factors and 12 year cardiovascular mortality for men screened in the Multiple Risk Factor Intervention Trial. Diabetes Care. 1993;16:434-444.

104. Lichtenstein MJ, Shipley MJ, Rose G. Systolic and diastolic blood pressures as predictors of coronary heart disease mortality in the Whitehall study. BMJ. 1985;291:243-245.

105. Turner RC, Millins H, Neil HAW, et al. Risk factors for coronary artery disease in non-insulin dependent diabetes mellitus: United Kingdom Prospective Diabetes Study (UKPDS). BMJ. 1998;346:823-828.

106. deFronzo R, Ferrannini E. Insulin resistance: a multifaceted syndrome responsible for NIDDM, obesity, hypertension, dyslipidemia, and atherosclerotic disease. Diabetes Care. 1991;14:173-194.

107. deFronzo RA, Goldberg M, Agus ZS. The effects of glucose and insulin on renal electrolyte transport. $J$ Clin Invest. 1976;58:83-90.

108. Hall JE, Summers RL, Brands MW, Keen H, Alonso-Galicia M. Resistance to metabolic actions of insulin and its role in hypertension. Am J Hypertens. 1994;7:772-788.

109. Capron L, Jarnet J, Kazandjian S, Housset E. Growth-promoting effects of diabetes and insulin on arteries: an in vivo study of rat aorta. Diabetes. 1986;35:973-978.

110. Anderson EA, Balon TW, Hoffman RP, Sinkey CA, Mark AL. Insulin increases sympathetic activity but not blood pressure in borderline hypertensive humans. Hypertension. 1992;19:621-627.

111. Goode GK, Miller JP, Heagerty AM. Hyperlipidemia, hypertension and coronary heart disease. Lancet. 1995;345:362-364.

112. Comitte of Prinicipal Investigators. A co-operative trial in the primary prevention of ischaemic heart disease using clofibrate. Br Heart $J$. 1978;40:1069-1118.

113. Calle EE, Thun MJ, Petrelli JM, Rodriguez C, Heath CW Jr. Body mass index and mortality in a prospective cohort of US adults. $N$ Engl J Med. 1999;341:1097-1105.
114. Barret-Conner EL. Obesity, atherosclerosis, and coronary heart disease. Ann Intern Med. 1985;103:1010-1019.

115. Yamauchi T, Kamon J, Waki H, et al. The fat-derived hormone adiponectin reverses insulin resistance associated both lipoatrophy and obesity. Nat Med. 2001;7:941-946.

116. Voulgari C, Moyssakis I, Papazafiropoulou A, et al. The impact of metabolic syndrome on left ventricular myocardial performance. Diabetes Metab Res Rev. 2010;26:121-127.

117. Mogensen CE. Microalbuminuria predicts clinical proteinuria and early mortality in maturity onset diabetes. $N$ Engl J Med. 1984;310: 356-360.

118. Manske CL, Wilson RF, Wang Y, Thomas W. Prevalence of, and risk factors for, angiographically determined coronary artery disease in type 1 diabetic patients with nephropathy. Arch Intern Med. 1992;152: 24500-24505.

119. Yudkin JS, Forrest RD, Jackson CA. Microalbuminuria as a predictor of vascular disease in non-diabetic subjects. Lancet. 1988;2:530-533.

120. Deckert T, Yokoyama H, Mathiesen E, et al. Cohort study of predictive value of urinary albumin excretion for atherosclerotic vascular disease in patients with insulin dependent diabetes. BMJ. 1996;312: 871-874.

121. Borch-Johnsen K, Kreiner S. Proteinuria: value as predictor of cardiovascular mortality in insulin-dependent diabetes mellitus. BMJ. 1989;294:1651-1654.

122. Dinneen SF, Gerstein HC. The association of microalbuminuria and mortality in non-insulin-dependent diabetes mellitus: a systematic overview of the literature. Arch Intern Med. 1997;157:1413-1418.

123. Fuller JH, Stevens LK, Wang SL; WHO Multinational Study Group. Risk Factors for cardiovascular mortality and morbidity: the WHO multinational study of vascular disease in diabetes. Diabetologia. 2001;44 Suppl 2:S54-S64.

124. Gruden G, Cavallo-Perin P, Bazzan M, Stella S, Vuolo A, Pagano G. PAI-1 and factor VII activity are higher in IDDM patients with microalbuminuria. Diabetes. 1994;43:426-429.

125. Bruno G, Cavallo-Perin P, Bargero G, Borra M, D’Errico N, Pagano G. Association of fibrinogen with glycemic control and albumin excretion rate in patients with non-insulin-dependent diabetes mellitus. Ann Intern Med. 1996;125:653-657.

126. Earle KS, Walker J, Hill C, Viberti G. Familial clustering of cardiovascular disease in patients with insulin-dependent diabetes and nephropathy. N Engl J Med. 1992;325:673-677.

127. Lee M, Gardin JM, Lynch JC, et al. Diabetes mellitus and echocardiographic left ventricular function in free-living elderly men and women: The Cardiovascular Health Study. Am Heart J. 1997;133:36-43.

128. Palmieri V, Bella JN, Arnett DK, et al. Effect of Type 2 Diabetes Mellitus on Left Ventricular Geometry and Systolic Function in Hypertensive Subjects: Hypertension Genetic Epidemiology Network (HyperGEN) Study. Circulation. 2001;103:102-107.

129. Ilercil A, Devereux RB, Roman MJ, et al. Relationship of impaired glucose tolerance to left ventricular structure and function: the Strong Heart Study. Am Heart J. 2001;141:992-998.

130. Struthers AD, Morris AD. Screening for and treating left ventricular abnormalities in diabetes mellitus: a new way of reducing cardiac deaths. Lancet. 2002;359:1430-1432.

131. Kimball TR, Daniels SR, Khoury PR, Magnotti RA, Turner AM, Dolan LM. Cardiovascular status in young patients with insulin dependent diabetes mellitus. Circulation. 1994;90:357-361.

132. Dumesnil JG, Gaudreault G, Honos GN, Kingma JG Jr. Use of Valsalva maneuver to unmask left ventricular diastolic function abnormalities by Doppler echocardiography in patients with coronary artery disease or systemic hypertension. Am J Cardiol. 1991;68:515-519.

133. Garneau C. Diastolic dysfunction in normotensive men with well controlled type 2 diabetes mellitus. Importance of manoeuvres in echocardiographic screening for preclinical diabetic cardiomyopathy. Diabetes Care. 2001;24:5-10.

134. Tei C. New non-invasive index for combined systolic and diastolic ventricular function. $J$ Cardiol. 1995;26:135-136. 
135. Tei C, Ling LH, Hodge DO, et al. New index of combined systolic and diastolic myocardial performance: a simple and reproducible measure of cardiac function: a study in normal and dilated cardiomyopathy. J Cardiol. 1995;26:357-366.

136. Poulsen SH, Nielsen JC, Andersen HR. The influence of heart rate on the Doppler-derived myocardial performance index. J Am Soc Echocardiogr. 2000;13:379-384.

137. Vinereanu D, Nicolaides E, Tweddel AC. Subclinical left ventricular dysfunction in asymptomatic patients with Type II diabetes mellitus, related to serum lipids and glycated haemoglobin. Clin Sci. 2003;105:591-599.

138. Gillebert TC, van de Veire N, de Buyzere ML, de Sutter J. Time intervals and global cardiac function. Use and limitations. Eur Heart J. 2004;25:2185-2186

139. Bruch C, Schmermund A, Marin D, et al. Tei-Index in patients with mild-to-moderate congestive heart failure. Eur Heart J. 2000;21: $1888-1895$.

140. Arnlöv J, Lind L, Andrén B, Risérus U, Berglund L, Lithell H. A Doppler-derived index of combined left ventricular systolic and diastolic function is an independent predictor of cardiovascular mortality in elderly men. Am Heart J. 2005;149:902-907.

141. Szczepaniak LS, Victor RG, Orci L, Unger RH. Forgotten but not gone: the rediscovery of fatty heart, the most common unrecognized disease in America. Circ Res. 2007;101:759-767.

142. Fang ZY, Yuda S, Anderson V, Short L, Case C, Marwick TH. Echocardiographic detection of early diabetic myocardial disease. J Am Coll Cardiol. 2003;41:611-617.

143. Fang ZY, Najos-Valencia O, Leano R, Marwick TH. Patients with early diabetic heart disease demonstrate a normal myocardial response to dobutamine. J Am Coll Cardiol. 2003;42:446-453.

144. Kosmala W, Kucharski W, Przewlocka-Kosmala M, Mazurek W. Comparison of left ventricular function by tissue doppler imaging in patients with diabetes mellitus without systemic hypertension vs diabetes mellitus with systemic hypertension. Am J Cardiol. 2004;94:395-399.

145. Guang-wei L, Ying-hua H, Wen-ying Y, et al. Effects of insulin resistance and insulin secretion on the efficacy of interventions to retard development of type 2 diabetes complications: the Da Qing IGT and diabetes study. Diabetes Res Clin Pract. 2002;58:193-200.

146. Tuomilehto J, Lindström J, Eriksson JG, et al; for the Finnish Diabetes Prevention Study Group. Prevention of type 2 diabetes mellitus by changes in lifestyle among subjects with impaired glucose tolerance. N Engl J Med. 2001;344:1343-1350.

147. Hu G, Tuomilehto J, Silventoinen K, Barengo N, Jousilahti P. Joint effects of physical activity, body mass index, waist circumference, and waist-to-hip ratio with the risk of cardiovascular disease among middleaged Finnish men and women. Eur Heart J. 2004;25:2212-2219.

148. Kempler P. Learning from large cardiovascular clinical trials: classical cardiovascular risk factors. Diabetes Res Clin Pract. 2005; 68 Suppl 1:S43-S47.

149. Hadden DR, Patterson CC, Atkinson AB, et al. Macrovascular disease and hyperglycemia: 10-year survival analysis in type 2 diabetes mellitus: the Belfast Diet Study. Diabet Med. 1997;14:663-672.

150. Hanefeld M, Fischer S, Julius U, et al; for the DIS group. Risk factors for myocardial infarction and death in newly detected NIDDM: the Diabetes Intervention Study, 11-year follow-up. Diabetologia. 1996; 39:1577-1583.

151. Meier M, Hummel M. Cardiovascular disease and intensive glucose control in type 2 diabetes mellitus: moving practice toward evidencebased strategies. Vasc Health Risk Manag. 2009;5:859-871.

152. UK Prospective Diabetes Study Group. Association of glycemia with macrovascular and microvascular complications of type 2 diabetes (UKPDS 35): prospective observational study. BMJ. 2000; 321:405-412.

153. Haffner SM. The Scandinavian Simvastatin Survival Study (4S) subgroup analysis of diabetic subjects: implications for the prevention of coronary heart disease. Diabetes Care. 1997;20:469-471.
154. Robins SJ, Collins D, Wittes JT, et al; for the VA-HIT group. Relation of gemfibrozil treatment and lipid levels with major coronary events: VA-HIT: a randomized controlled trial. JAMA. 2001;285:1585-1591.

155. Rubins HB, Robins SJ, Collins D, et al; for the VA-HIT study group. Diabetes, plasma insulin, and cardiovascular disease: subgroup analysis from the Department of Veterans Affairs High-density lipoprotein intervention Trial (VA-HIT). Arch Intern Med. 2002;162: 2597-2604.

156. Robins SJ, Collins D, McNamara JR, Bloomfield HE. Body weight, plasma insulin, and coronary events with gemfibrozil in the Veterans Affairs High-Density Lipoprotein Intervention Trial (VA-HIT). Atherosclerosis. 2008;196(2):849-855.

157. Jones PH. Expert perspective: reducing cardiovascular risk in metabolic syndrome and type 2 diabetes mellitus beyond low-density lipoprotein cholesterol lowering. Am J Cardiol. 2008;102(12A):41L-47L.

158. The ALLHAT officers and coordinators for the ALLHAT collaborative research study. Major outcomes in high-risk hypertensive patients randomized to ACE inhibitors or calcium channel blocker vs diuretic. The Antihypertensive and Lipid-Lowering Treatment to Prevent Heart Attack trial (ALLHAT). JAMA. 2002;288:2981-2997.

159. The Heart Outcomes Prevention Evaluation Study Investigators. Effects of an angiotensin-converting-enzyme inhibitor, ramipril, on cardiovascular events in high-risk patients. $N$ Engl J Med. 2000;342: 145-153.

160. Hansson L, Zachetti A, Carruthers SG, et al; for the HOT study group. Effects of intensive blood-pressure lowering and lowdose aspirin in patients with hypertension; principal results of the Hypertension Optimal Treatment (HOT) randomized trial. Lancet. 1998;351:1755-1762.

161. Lindholm LH, Ibsen H, Dalhof B; for the LIFE Study group. Cardiovascular morbidity and mortality in patients with diabetes in the Losartan Intervention for Endpoint reduction in hypertension study (LIFE): a randomized trial against atenolol. Lancet. 2002;359:1004-1010.

162. UK Prospective Diabetes Study Group. Tight blood pressure control and risk of macrovascular complications in type 2 diabetes: UKPDS 38. BMJ. 1998;317:703-711.

163. Holman R, Turner R, Stratton I, et al; UK Prospective Diabetes Study Group. Efficacy of atenolol and captopril in reducing risk of macrovascular and microvascular complications in type 2 diabetes: UKPDS 39. BMJ. 1998;317:713-720.

164. Lewis EJ, Hunsicker LG, Clarke WR, et al; for the collaborative study group. Renoprotective effect of the angiotensin-receptor antagonist irbesartan in patients with nephropathy due to type 2 diabetes. $N$ Engl J Med. 2001;345:851-860.

165. Bristow MR. Beta-adrenergic receptor blockade in chronic heart failure. Circulation. 2000;101:558-569.

166. The CURE Study Investigators. The Clopidogrel in Unstable Angina to prevent Recurrent Events Study. Effects of clopidogrel in addition to aspirin in patients with acute coronary syndromes without STsegment elevation. The Clopidogrel in Unstable Angina to Prevent Recurrent Events Trial Investigators. N Engl J Med. 2001;345: 494-502.

167. Falcão-Pires I, Gonçalves N, Gavina C, et al. Correlation between plasma levels of apelin and myocardial hypertrophy in rats and humans: possible target for treatment? Expert Opin Ther Targets. 2010;14:231-241.

168. Savvatis K, Westermann D, Schultheiss HP, Tschöpe C. Kinins in cardiac inflammation and regeneration: insights from ischemic and diabetic cardiomyopathy. Neuropeptides. 2010;44(2):119-125.

169. Sulaiman M, Matta MJ, Sundaresan NR, et al. Resveratrol, an activator of SIRT1 up-regulates sarcoplasmic calcium ATPase and improves cardiac function in diabetic cardiomyopathy. Am J Physiol Heart Circ Physiol. 2010;298:H833-843.

170. Kohda Y, Kanematsu M, Kono T, Terasaki F, Tanaka T. Protein O-glycosylation induces collagen expression and contributes to diabetic cardiomyopathy in rat cardiac fibroblasts. J Pharmacol Sci. 2009;111:446-450. 
171. Aydemir-Koksoy A, Bilginoglu A, Sariahmetoglu M, Schulz R, Turan B. Antioxidant treatment protects diabetic rats from cardiac dysfunction by preserving contractile protein targets of oxidative stress. J Nutr Biochem. 2009. doi:10.1016/j.jnutbio.2009.06.006.

172. Li CJ, Zhang QM, Li MZ, Zhang JY, Yu P, Yu DM. Attenuation of myocardial apoptosis by alpha-lipoic acid through suppression of mitochondrial oxidative stress to reduce diabetic cardiomyopathy. Chin Med J (Engl). 2009;122:2580-2586.

173. Hotta H, Miura T, Miki T, et al. Angiotensin II type 1 receptor-mediated upregulation of calcineurin activity underlies impairment of cardioprotective signaling in diabetic hearts. Circ Res. 2010;106:129-232.

174. Wang M, Zhang WB, Zhu JH, Fu GS, Zhou BQ. Breviscapine ameliorates cardiac dysfunction and regulates the myocardial $\mathrm{Ca}(2+)$-cycling proteins in streptozotocin-induced diabetic rats. Acta Diabetol. 2009. doi 10.1007/s00592-009-0164-X.

175. Wang M, Zhang WB, Zhu JH, Fu GS, Zhou BQ. Breviscapine ameliorates hypertrophy of cardiomyocytes induced by high glucose in diabetic rats via the PKC signaling pathway. Acta Pharmacol Sin. 2009;30(8):1081-1091.

176. Connelly KA, Kelly DJ, Zhang Y, et al. Inhibition of protein kinase $\mathrm{C}$-beta by ruboxistaurin preserves cardiac function and reduces extracellular matrix production in diabetic cardiomyopathy. Circ Heart Fail. 2009;2:129-137.

177. Chao PC, Hsu CC, Yin MC. Anti-inflammatory and anti-coagulatory activities of caffeic acid and ellagic acid in cardiac tissue of diabetic mice. Nutr Metab (Lond). 2009;6:33.

178. Xi S, Zhou G, Zhang X, Zhang W, Cai L, Zhao C. Protective effect of total aralosides of Aralia elata (Miq) Seem (TASAES) against diabetic cardiomyopathy in rats during the early stage, and possible mechanisms. Exp Mol Med. 2009;41:538-547.
179. Schneider R, Welt K, Aust W, Löster H, Fitzl G. Cardiac ischemia and reperfusion in spontaneously diabetic rats with and without application of EGb 761: II. Interstitium and microvasculature. Histol Histopathol. 2009;24:587-598.

180. Schneider R, Welt K, Aust W, Löster H, Fitzl G. Cardiac ischemia and reperfusion in spontaneously diabetic rats with and without application of EGb 761: I. cardiomyocytes. Histol Histopathol. 2008;23:807-817.

181. Cheng M, Gao HQ, Xu L, Li BY, Zhang H, Li XH. Cardioprotective effects of grape seed proanthocyanidins extracts in streptozocin induced diabetic rats. J Cardiovasc Pharmacol. 2007;50:503-509.

182. Shushakova N, Park JK, Menne J, Fliser D. Chronic erythropoietin treatment affects different molecular pathways of diabetic cardiomyopathy in mouse. Eur J Clin Invest. 2009;39:755-760.

183. Chachques JC. Cellular cardiac regenerative therapy in which patients? Expert Rev Cardiovasc Ther. 2009;7:911-919.

184. Boudina S, Abel ED. Diabetic cardiomyopathy revisited. Circulation. 2007;115:3213-3223.

185. Aneja A, Tang WH, Bansilal S, Garcia MJ, Farkouh ME. Diabetic cardiomyopathy: insights into pathogenesis, diagnostic challenges, and therapeutic options. Am J Med. 2008;121:748-757.

186. Khavandi K, Khavandi A, Asghar O, et al. Diabetic cardiomyopathy a distinct disease? Best Pract Res Clin Endocrinol Metab. 2009;23: 347-360.

187. Asghar O, Al-Sunni A, Khavandi K, et al. Diabetic cardiomyopathy. Clin Sci (Lond). 2009;116:741-760.
Vascular Health and Risk Management

\section{Publish your work in this journal}

Vascular Health and Risk Management is an international, peerreviewed journal of therapeutics and risk management, focusing on concise rapid reporting of clinical studies on the processes involved in the maintenance of vascular health; the monitoring, prevention and treatment of vascular disease and its sequelae; and the involvement of

\section{Dovepress}

metabolic disorders, particularly diabetes. This journal is indexed on PubMed Central and MedLine. The manuscript management system is completely online and includes a very quick and fair peer-review system, which is all easy to use. Visit http://www.dovepress.com/ testimonials.php to read real quotes from published authors. 